\title{
Does supplementation with mitochondria improve oocyte competence? A systematic review
}

\author{
Ana Filipa Ferreira ${ }^{1,2}$, Maria Soares ${ }^{3}$, Sandra Almeida Reis ${ }^{3,4}$, João Ramalho-Santos ${ }^{3,5}$, \\ Ana Paula Sousa ${ }^{1,3}$ and Teresa Almeida-Santos ${ }^{1,2,3}$ \\ ${ }^{1}$ Reproductive Medicine Unit, Centro Hospitalar e Universitário de Coimbra, Praceta, Coimbra, Portugal, ${ }^{2}$ University \\ of Coimbra, Faculty of Medicine, Azinhaga de Santa Comba, Celas, Coimbra, Portugal, ${ }^{3} \mathrm{CNC}-$ Center for \\ Neuroscience and Cell Biology, CIBB, Azinhaga de Santa Comba, Celas, University of Coimbra, Coimbra, Portugal, \\ ${ }^{4}$ PhD Programme in Experimental Biology and Biomedicine, IIIUC - Institute for Interdisciplinary Research, \\ University of Coimbra, Coimbra, Portugal and ${ }^{5}$ Department of Life Sciences, University of Coimbra, Calçada Martim \\ de Freitas, Coimbra, Portugal
}

Correspondence should be addressed to A F Ferreira; Email: filipaferreira44@gmail.com

\begin{abstract}
Mitochondrial supplementation was proposed as a complementary treatment to assisted reproductive technologies to improve oocyte competence and support post-fertilization development. This strategy is based on the fact that poor-quality/aged oocytes contain lower and dysfunctional mitochondria. However, the efficacy and safety of mitochondrial supplementation are still controversial. Therefore, this review summarizes the clinical/biological outcomes of mitochondrial supplementation, aiming to improve oocyte competence or explore the safety of this technique, and was based on an online search using PubMed and Web of Science, until September 2019. The studies included reported outcomes related to the efficacy and safety of mitochondrial supplementation either in human or animal models (bovine, porcine and mouse). Extracted data were organized according to study objective, the mitochondrial source and the main outcomes: fertilization/pregnancy rates, embryo development and adverse outcomes. Clinical pregnancy was not improved in the only randomized controlled trial published, although an increase was demonstrated in other non-randomized studies. Fertilization rate and embryo development were not different from control groups in the majority of studies, although performed in different contexts and using diverse sources of mitochondria. The safety of mitochondria transfer is still a concern, however, the euploid rate and the absence of reported congenital malformation from the clinical studies are reassuring. In summary, mitochondrial supplementation does not seem to cause harm although the benefit of improving oocyte competence is still unclear due to the diversity of methodological approaches and low-quality of the data available. Analyzed data support the need to investigate further, in both pre-clinical and clinical contexts.

Reproduction (2021) 161 269-287
\end{abstract}

\section{Introduction}

Ooplasm transfer from a young donor into oocytes of a 39-year-old woman was performed for the first time in 1997 by Cohen and coworkers, in the context of poor embryo development, resulting in the birth of a healthy child (Cohen et al. 1997). Restoration of normal growth in developmentally compromised oocytes was then achieved by these and other authors, resulting in the birth of nearly 30 babies worldwide (Barritt et al. 2001a). The mechanism by which cytoplasmic transfer restored oocyte competence was unknown at that time. Some hypotheses were proposed, including the introduction of cytoplasmic factors, such as maturation promoting factors (Petr et al. 1994) and inhibitory factors (proteins or RNAs) (Cohen et al. 1998, Dale et al. 2001), the transfer of mRNA and organelles involved in oocyte function and embryo development (Cohen et al. 1998, Barritt et al. 2001a) and the transfer of mitochondria, that could be responsible for the oocyte metabolic activity increase (Van Blerkom et al. 1998, Barritt et al. 2001a).

Nowadays, a growing body of evidence supports the mitochondrial hypothesis, with data obtained in a variety of species and model systems. Oocytes with an immature status (when extrusion of the first polar body is not observed) or unfertilized (when no pronuclei or second polar body are observed) are considered to be of poor quality. These (poor-quality) oocytes, have been associated with lower copies of mitochondrial DNA (mtDNA) (May-Panloup et al. 2005, Santos et al. 2006) and mitochondrial dysfunction (Eichenlaub-Ritter et al. 2011, Schatten et al. 2014). Also, a poor mitochondrial content and mtDNA deletions were observed in lowerquality oocytes from older women (Keefe et al. 1995, 
Chan et al. 2005, Duran et al. 2011). Mitochondria are responsible for cellular energy production and have a pivotal role in oocyte competence. Mitochondria possess their own genome in the form of a doublestranded circular molecule that encodes 13 proteins comprising the electron transport chain (ETC), 22 tRNA and 2 rRNA. Additionally, other proteins of the ETC and the mitochondrion are encoded by the nuclear genome. Therefore, the coordination of the expression of genes (or the processes of transcription and translation) from both mitochondrial and nuclear genomes is important to maintain the normal cellular function (EichenlaubRitter et al. 2011, May-Panloup et al. 2016).

The important contribution of mitochondria on meiotic spindle formation and maintenance is supported by the detrimental consequences that lower levels of ATP production have on chromosome segregation and embryo development (Van Blerkom et al. 1995, Eichenlaub-Ritter 1998, Schon et al. 2000, Igarashi et al. 2005). Furthermore, oocytes with higher levels of mtDNA copy number $(209,000 \pm 122,000 \mathrm{vs}$ $152,000 \pm 90,000)$ have been associated with higher fertilization rates (Reynier et al. 2001) and, in porcine mature oocytes, with higher fertilization and blastocyst rates (Cagnone et al. 2016). On the other hand, preimplantation development was not compromised in mouse mature oocytes with lower copies of mtDNA, but there was a critical threshold for postimplantation development (Wai et al. 2010). It seems that both preimplantation and postimplantation development can be disturbed by a lower content of mtDNA in the oocyte.

There is, therefore, in theory, a potential benefit of increasing the number of healthy/active mitochondria into oocytes. However, the efficacy and safety of mitochondrial transfer as a complementary treatment for assisted reproductive technologies (ART) is still controversial. Clinical research indicates that mitochondrial transfer can rescue compromised oocytes (Huang et al. 2018), although a recent randomized pilot trial (RCT) failed to demonstrate higher fertilization or pregnancy rates (Labarta et al. 2019b). Other studies in humans demonstrated that cytoplasmic transfer leads to an increase in pregnancy rates (Cohen et al. 1997, 1998, Huang et al. 1999, Dale et al. 2001), presumably by introducing more mitochondria. This procedure was also tested in animal species with higher fertilization and embryo development rates observed in a bovine (Hua et al. 2007, Chiaratti et al. 2011) and porcine (El Shourbagy et al. 2006, Cagnone et al. 2016) model. However, other studies have shown no differences in these outcomes with mitochondrial supplementation (Nagai et al. 2004, Igarashi et al. 2016, Li et al. 2017, Sheng et al. 2019).

Both the context in which this procedure has been used and the source of mitochondria are noteworthy. Allogenic ooplasm transfer was first used, but concerns emerged on its safety after reported cases of Turner syndrome and autism (Barritt et al. 2001a). In 2001, the Food and Drug Administration (FDA) suspended the use of therapies involving the transfer of genetic material, including mitochondrial genetic material from the ooplasm, advocating ethical and biological concerns, namely the risk of generating a heteroplasmic mitochondrial population (https://wayback.archive-it. org/7993/20170404210748/https://www.fda.gov/ BiologicsBloodVaccines/SafetyAvailability/ucm 105852. htm. Accessed May 11, 2020). In fact, mitochondrial donor population has been confirmed in two of the children born after ooplasmic transfer, although no malformations were reported (Barritt et al. 2001b). Even though low levels of heteroplasmy are normally present, cells of an individual are usually homoplasmic, carrying only one mitochondrial population (one genome), that is maternally transmitted. Paternal mitochondria are believed to be destroyed after fertilization and therefore, mitochondria transmission over generations is dependent on oocyte mitochondria content. In addition, subpopulations of mitochondria may be preferentially replicated during oogenesis, according to the bottleneck theory (Mishra \& Chan 2014). To overcome the question raised with FDA announcement, autologous sources of mitochondria are being used in more recent studies.

There are several studies that sought to determine the efficacy and safety of oocyte mitochondrial supplementation, as well as its consequences at the molecular level. However, the evidence has not yet been adequately organized.

The aim of our systematic review was to assess the safety and efficacy of mitochondrial supplementation to improve oocyte competence. Therefore, we critically review data from both human studies and animal models addressing embryo development, fertilization and pregnancy rates, and adverse outcomes. In addition, we analyzed the outcomes that support clinical evidence, related to parameters that are relevant in this context, such as mtDNA copy number, ATP content and patterns of gene expression.

\section{Methods}

\section{Search strategy}

The study selection process for this systematic review was based on PRISMA Guidelines (Liberati et al. 2009). A systematic literature review to assess the studies investigating the effect of oocyte mitochondrial supplementation was based on an online search using PubMed (MEDLINE database) and Web of Science until September 2019.

The search terms used to identify the studies were 'mitochondri* (e.g. mitochondria, mitochondrial and mitochondrion) supplementation', 'mitochondri* transfer', 'mitochondri* injection', 'mitochondri* microinjection', ooplasm* (e.g. ooplasm and ooplasmic), 'ooplasm* injection', 'cytoplasm* (e.g. cytoplasm and cytoplasmic) transfer' or 'cytoplasm* injection', and 'oocyte' or 'embryo'. 


\section{Study selection}

Studies were selected by three independent subjects. Studies were first screened for eligibility using article titles and then by reading the study abstracts.

We included clinical (experimental or observational) and animal studies performing mitochondrial transfer, either isolated or within cytoplasm, into fertilized/activated oocytes, designed to improve oocyte competence or explore the safety of this technique. Studies with non-mammalian species were excluded. Narratives, reviews, commentaries, letters to editor and abstract meeting were also excluded, as well as articles with full text in a language other than English, French, Portuguese or Spanish.

\section{Data extraction process}

Data on publication date, species, context (study objective), methods (cytoplasm vs mitochondria, source of mitochondria, study outcomes (clinical and biological measurements, molecular parameters) and quality scores were extracted from relevant manuscripts. Data extraction was independently performed by two authors (AFF and MS) and validated by a third author (SAR). If any doubt remained, the full text of the article was discussed. Arbitration by the third author was applied in cases of divergence of opinion.

\section{Quality assessment}

The risk of bias of the included studies was evaluated using the SYstematic Review Centre for Laboratory animal Experimentation SYRCLE's tool (Hooijmans et al. 2014). The SYRCLE's tool was adapted from the Cochrane risk of bias to assess the methodological quality of animal interventional studies. We have applied this scale to the 36 included studies with slight adaptations for clinical studies.

The score was judged according to the risk of bias: 'Yes' indicates a low risk of bias, 'No' indicates a high risk of bias, 'Unclear' indicates that data supplied was insufficient to assess the risk of bias and 'NA - not applicable' indicates inability to apply this item.

In order to attribute a quality score, 10 different criteria were measured: (1) random allocation sequence; (2) baseline characteristics; (3) allocation concealment; (4) random housing; (5) blinded intervention; (6) random outcome assessment; (7) blinded assessment of outcome; (8) incomplete outcome data; (9) selective outcome reporting; (10) other sources of bias. The criteria 'other source of bias' was defined by authors, concerning the mitochondrial extraction protocol, to evaluate specifically the description of the protocol and the evaluation of mitochondria activity.

\section{Results}

A total of 36 studies were included in the review. The initial search of databases identified 4695 citations. After screening the titles and abstracts, 68 full texts were obtained for detailed review. The process of selection is illustrated in Fig. 1.

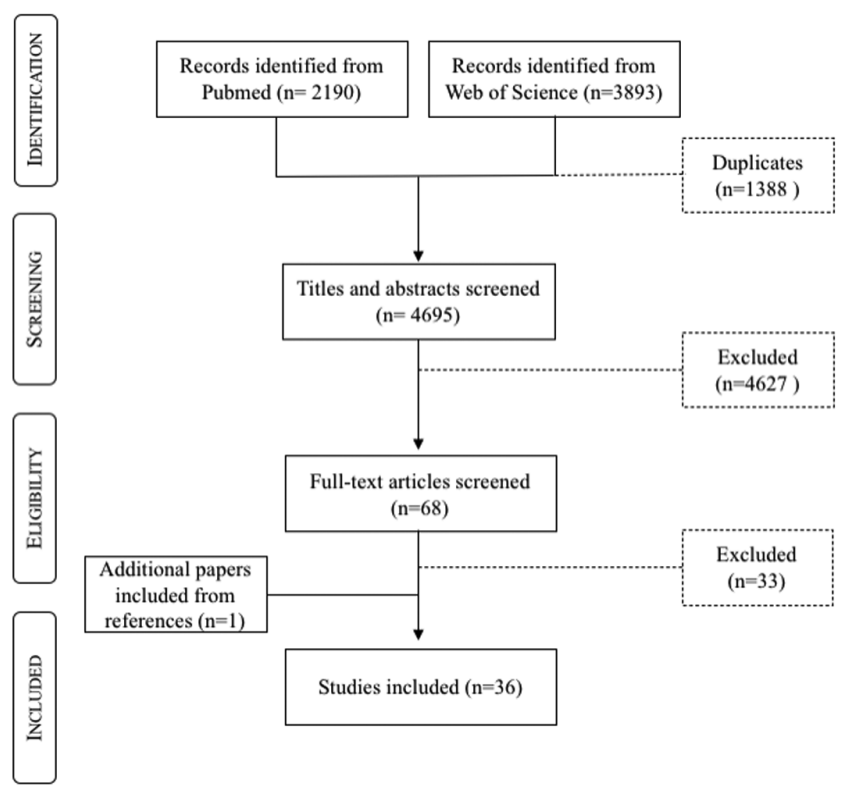

Figure 1 PRISMA flow diagram for a systematic review of the efficacy and safety of oocyte mitochondrial supplementation.

Data was organized according to the context of the investigation, the methods (i.e. transferred material and cell source) and the main outcomes resulting from the clinical and experimental studies. The details of the quality assessment are displayed in Fig. 2.

\section{Context (objectives of studies)}

Human studies (12 out of 36 studies) were performed in the context of infertile patients with poor embryo quality or advanced maternal age. The aim was to verify if mitochondrial (Fakih 2015, Oktay et al. 2015, Labarta et al. 2019b) or ooplasmic transfer (Cohen et al. 1997, 1998, Huang et al. 1999, Lanzendorf et al. 1999, Dale et al. 2001) could improve oocyte competence and hence the prognosis of the patients with previous in vitro fertilization (IVF) failures. Two studies were designed to evaluate the clinical efficacy of this procedure in women with advanced maternal age (Lanzendorf et al. 1999, Kong et al. 2003) and two others to evaluate the degree of mitochondrial heteroplasmy after ooplasmic transfer (Brenner et al. 2000, Barritt et al. 2001b). One study was conducted with the purpose of evaluating the effect of cytoplasmic transfer on promoting oocyte maturation (Hoseini et al. 2016).

The majority of the experimental studies (14 out of 24) were conducted in animals with good quality oocytes. The effects of mitochondrial transfer were evaluated by comparing IVF/ICSI (intracytoplasmic sperm injection) vs mitochondrial supplementation in combination with ICSI (mICSI) (Li et al. 2017, Tsai \& St John 2018) or by comparing somatic cell nuclear transfer (SCNT) in animals of the same species (Lee et al. 2017, Srirattana 


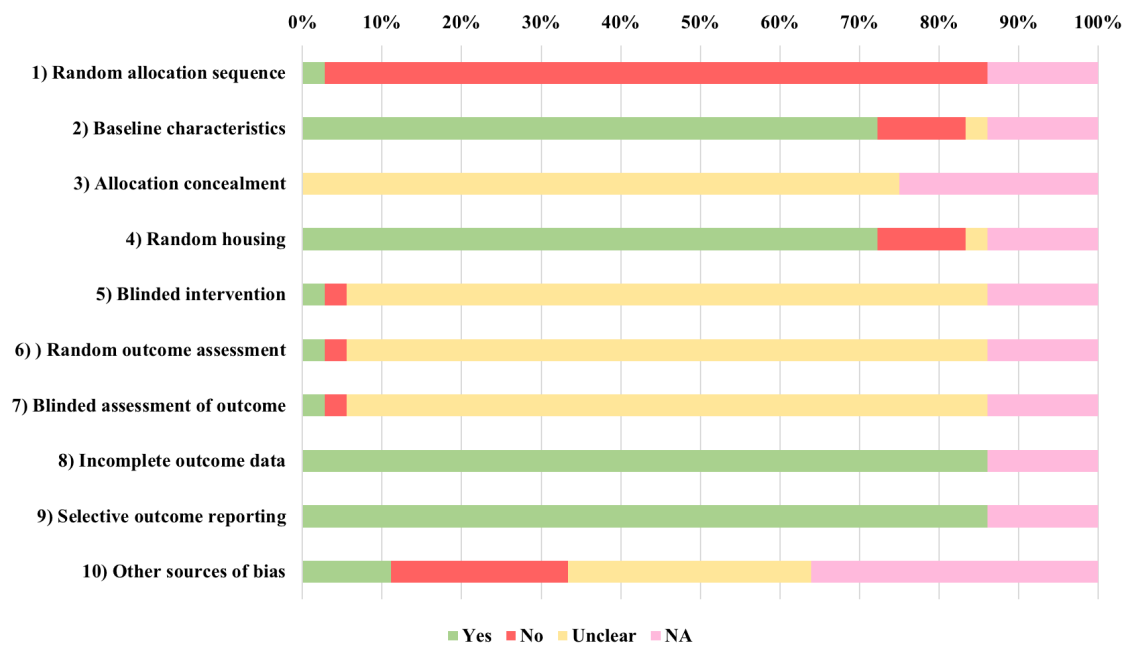

Figure 2 Risk of bias per item. Percentages at top refer to percentages of included studies with a particular risk of bias score. Yes, low risk of bias; No, high risk of bias; Unclear, unclear risk of bias; NA, not applicable.
\& St John 2018, Xu et al. 2019) or involving different species (iSCNT) (Sansinena et al. 2011, Hua et al. 2012, Takeda et al. 2012, Gonzalez-Grajales et al. 2016), with or without mitochondrial transfer. Mitochondrial transfer was also compared in the context of parthenogenetic development in bovine species (Takeda et al. 2005). Two studies were designed to evaluate different volumes of injected cytoplasm in mouse species (Nagai et al. 2004, Van Thuan et al. 2006).

Six studies (Petr et al. 1994, El Shourbagy et al. 2006, Hua et al. 2007, Chiaratti et al. 2011, Cagnone et al. 2016, Tsai et al. 2018) were performed in the context of poor oocyte quality while models of aging were explored in three other studies using mouse species (Yi et al. 2007, Igarashi et al. 2016, Sheng et al. 2019). The purpose of these studies was to evaluate oocyte quality and embryonic development after mitochondrial/ooplasmic transfer. Some studies evaluated the effect of this procedure on oocyte/embryo gene expression profiles (Tsai \& St John 2018, Tsai et al. 2018) and others have tried to correlate the outcomes with the amount of mtDNA copies (Takeda et al. 2012, Cagnone et al. 2016, Srirattana \& St John 2018, Sheng et al. 2019), the ATP content (Van Blerkom et al. 1998, Gonzalez-Grajales et al. 2016, Sheng et al. 2019) and gene expression profile alterations (Hua et al. 2012, Cagnone et al. 2016, GonzalezGrajales et al. 2016, Srirattana \& St John 2018).

Some of these authors have also explored the safety of the technique (Chiaratti et al. 2011, Hua et al. 2012, $\mathrm{Li}$ et al. 2017) whereas another study was designed to evaluate the transgenerational effects of mitochondrial transfer in mouse species (St John et al. 2019).

\section{Mitochondrial vs cytoplasmic transfer and cell source of transplanted mitochondria}

The supplementation of isolated mitochondria was reported in 20 papers while cytoplasmic transfer was reported in 16. The material used to supplement oocytes was obtained from different cell types as illustrated in Fig. 3.
The major source of isolated mitochondria was oocyte (Van Blerkom et al. 1998, El Shourbagy et al. 2006, Cagnone et al. 2016, Srirattana \& St John 2018, Tsai \& St John 2018, Tsai et al. 2018) and egg precursor cells (EPC) (Fakih 2015, Oktay et al. 2015, Labarta et al. 2019b, St John et al. 2019). Somatic cells were used in six studies, with mitochondria recovered from liver (Yi et al. 2007, Igarashi et al. 2016) or from granulosa/ cumulus cells (Kong et al. 2003, Takeda et al. 2005, Hua et al. 2007, 2012) and other cell types were used in four studies, including adipose tissue stem cells (Wang et al. 2017b, Sheng et al. 2019) or fibroblastderived induced pluripotent stem cells (Takeda et al. 2012, Li et al. 2017).

Regarding cytoplasmic transfer, three types of cell were used as sources: oocytes (Cohen et al. 1997, 1998, Huang et al. 1999, Lanzendorf et al. 1999, Brenner et al. 2000, Barritt et al. 2001b, Dale et al. 2001, Nagai et al. 2004, Chiaratti et al. 2011,

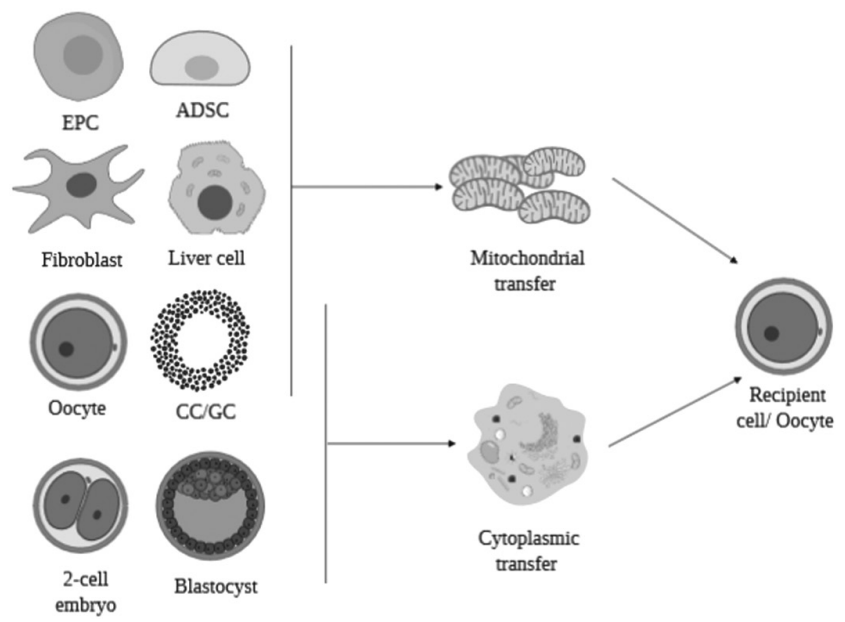

Figure 3 Illustration of the different cell sources used for oocyte mitochondrial supplementation. EPC, egg precursor cells; ADSC, adipose-derived stem cells; CC, cumulus cells; GC, granulosa cells. 
Table 1 Summary of human studies evaluating clinical and biological measures.

\begin{tabular}{|c|c|c|c|c|c|c|}
\hline Source & Context & Incr. FR & Impr. ED & Incr. pregnancy & $\begin{array}{l}\text { Offspring and } \\
\text { adverse outcomes }\end{array}$ & References \\
\hline $\begin{array}{l}\text { Autologous } \\
\text { EPC-mitochondria }\end{array}$ & $\begin{array}{l}\text { Poor embryo quality } \\
\text { - mICSI vs ICSI }\end{array}$ & $x$ & $x$ & $x$ & $\begin{array}{l}\text { Seven healthy } \\
\text { children born }\end{array}$ & $\begin{array}{l}\text { Labarta et al. } \\
(2019 b)\end{array}$ \\
\hline $\begin{array}{l}\text { Autologous OPC- } \\
\text { mitochondria }\end{array}$ & $\begin{array}{l}\text { Poor oocyte/embryo } \\
\text { quality }\end{array}$ & $\checkmark$ & $x$ & $\checkmark$ & $\begin{array}{l}\text { One healthy child and } \\
\text { one ongoing pregnancy }\end{array}$ & $\begin{array}{l}\text { Oktay et al. } \\
(2015)\end{array}$ \\
\hline $\begin{array}{l}\text { Autologous OPC- } \\
\text { mitochondria }\end{array}$ & $\begin{array}{l}\text { Poor oocyte/embryo } \\
\text { quality }\end{array}$ & $x$ & $\checkmark$ & $\checkmark$ & 20 ongoing pregnancies & $\begin{array}{l}\text { Fakih et al. } \\
(2015)\end{array}$ \\
\hline $\begin{array}{l}\text { Granulosa } \\
\text { cell-mitochondria }\end{array}$ & Aging & NE & NE & $\begin{array}{l}\text { Pregnancy in a } \\
46 \text {-year-old }\end{array}$ & $\begin{array}{l}\text { Spontaneous abortion } \\
\text { at 9th week }\end{array}$ & $\begin{array}{l}\text { Kong et al. } \\
(2003)\end{array}$ \\
\hline $\begin{array}{l}\text { Allogenic ooplasm } \\
\text { (young donor) }\end{array}$ & Poor embryo quality & NE & $\checkmark$ & $\begin{array}{l}\text { Pregnancy } \\
\text { achieved }\end{array}$ & Birth of healthy twins & $\begin{array}{l}\text { Dale et al. } \\
(2001)\end{array}$ \\
\hline Allogenic ooplasm & Poor embryo quality & $\mathrm{NE}$ & $\mathrm{NE}$ & NE & $\begin{array}{l}\text { Mitochondrial heteroplasmy; } \\
\text { two healthy children }\end{array}$ & $\begin{array}{l}\text { Barritt et al. } \\
(2001 b)\end{array}$ \\
\hline Allogenic ooplasm & Poor embryo quality & NE & $\mathrm{NE}$ & $\mathrm{NE}$ & $\begin{array}{l}\text { Mitochondrial heteroplasmy } \\
\text { in } 2 / 4 \text { babies; one healthy } \\
\text { child (no information on } \\
\text { the others) }\end{array}$ & $\begin{array}{l}\text { Brenner et al. } \\
(2000)\end{array}$ \\
\hline $\begin{array}{l}\text { Allogenic-ooplasm } \\
\text { (young donor) }\end{array}$ & $\begin{array}{l}\text { Aging and poor } \\
\text { embryo quality }\end{array}$ & $x$ & $x$ & $\begin{array}{l}\text { Pregnancy in } \\
1 / 4 \text { patient }\end{array}$ & Birth of healthy twins & $\begin{array}{l}\text { Lanzendorf } \\
\text { et al. (1999) }\end{array}$ \\
\hline $\begin{array}{l}\text { Allogenic cytoplasm } \\
\text { (tripronucleate zygotes } \\
\text { from young donors) }\end{array}$ & Poor embryo quality & $x$ & $x$ & $\checkmark$ & $\begin{array}{l}\text { Five healthy infants with } \\
\text { normal karyotype }\end{array}$ & $\begin{array}{l}\text { Huang et al. } \\
\text { (1999) }\end{array}$ \\
\hline Allogenic ooplasm & Poor embryo quality & $\checkmark$ & $\checkmark$ & $\checkmark$ & $\begin{array}{l}\text { One live birth and one } \\
\text { ongoing pregnancy; } \\
\text { normal karyotypes }\end{array}$ & $\begin{array}{l}\text { Cohen et al. } \\
\text { (1998) }\end{array}$ \\
\hline Allogenic ooplasm & Poor embryo quality & NE & $\checkmark$ & $\begin{array}{l}\text { Pregnancy } \\
\text { achieved }\end{array}$ & $\begin{array}{l}\text { One live birth with } \\
\text { normal karyotype }\end{array}$ & $\begin{array}{l}\text { Cohen et al. } \\
\text { (1997) }\end{array}$ \\
\hline
\end{tabular}

Incr., increased; Impr., improved; FR, fertilizatiion rate; ED, embryo development

Sansinena et al. 2011, Gonzalez-Grajales et al. 2016, Hoseini et al. 2016), granulosa/cumulus cell (Van Thuan et al. 2006), and zygotes/embryos (Huang et al. 1999, Van Thuan et al. 2006). Three papers reported the evaluation of isolated mitochondrial function prior to oocyte supplementation. Mitochondrial membrane potential was determined using the fluorescent probe JC-1 (Hua et al. 2012, Sheng et al. 2019), oxygen consumption rate was determined by highresolution respirometry (Cagnone et al. 2016) and ATP production was assessed by an ATP bioluminescence assay (Sheng et al. 2019). Mitochondria morphology (assessed by transmission electron microscopy) (Wang et al. 2017b) and mitochondrial content (evaluated by quantification of mtDNA copy number with RT-PCR) (Hua et al. 2012, Cagnone et al. 2016) were also assessed prior to mitochondrial transfer. Additionally, and to confirm that oocytes were indeed injected with isolated mitochondria, several studies labeled mitochondria with MitoTracker Green probe (EI Shourbagy et al. 2006, Hua et al. 2007, Takeda et al. 2012, Cagnone et al. 2016, Igarashi et al. 2016) or Red Fluorescent Protein (RFP) (Li et al. 2017).

\section{Outcomes}

The outcome measures were categorized in clinical and biological measures, including fertilization and pregnancy rates, embryo development, the existence of offspring and adverse outcomes (summarized in
Table 1 - human studies, and Table 2 - animal models), and molecular parameters, including gene expression patterns, mtDNA copy number and ATP content (summarized in Table 3).

\section{Clinical outcomes}

There were 11 out of 36 studies assessing clinical outcomes. Autologous mitochondrial transfer, a treatment also referred to as AUGMENT was evaluated at four international fertility centers. Clinical pregnancy rate was not improved in the randomized controlled trial (RCT) conducted in Spain $(n=59)$ by Labarta et al. (2019b). The cumulative ongoing pregnancy and live birth rate per transferred embryo was $41.2 \%$ in the AUGMENT group and $41.7 \%$ in the control group. An increased clinical pregnancy rate was demonstrated in the other three nonrandomized, experimental studies, in which the control group was the group's historical IVF outcome. Fakih (2015), reported the clinical experience from two centers: Canada $(n=34)$ and The United Arab Emirates - UAE $(n=59)$, reporting a clinical pregnancy rate of 35 and $22 \%$, respectively, in the AUGMENT group, compared to 11 and $4 \%$, respectively, in the previous clinical pregnancy rate. At FAKIH IVF (in UAE), a comparison between treatment group (AUGMENT, $n=171$ ) and control group (ICSI, $n=106$ ) was also performed in a subgroup of 25 women. Embryo quality was higher in the AUGMENT group (embryo transfer performed in 


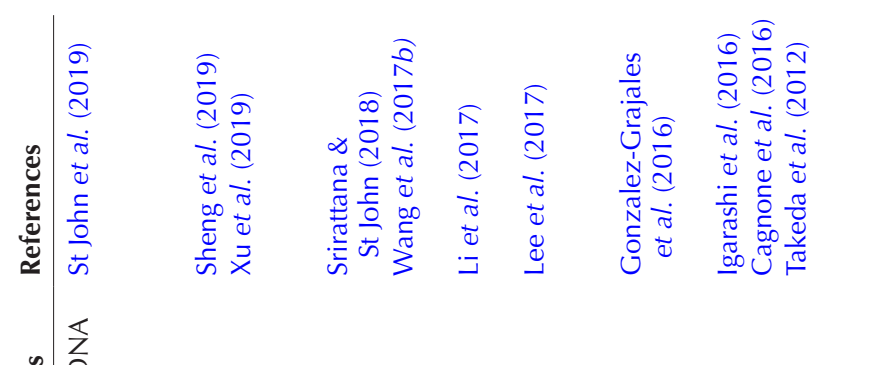

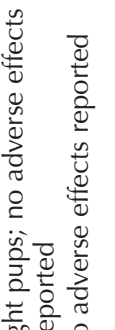

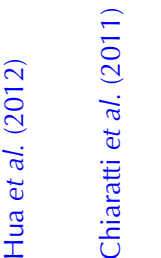

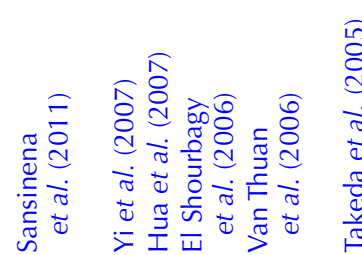

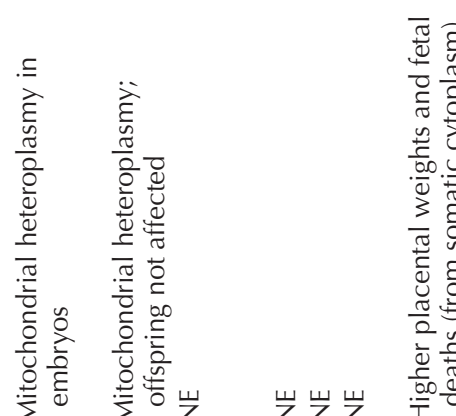

焉寅

는

这

घ

党

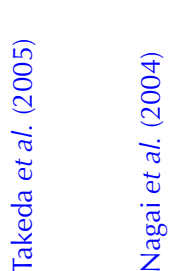

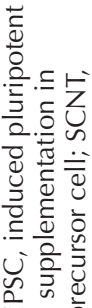

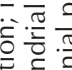

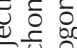

응

हैं

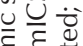

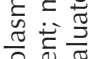

응

혼응

吾㟧

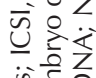

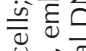

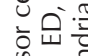

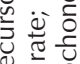

흐을

品:

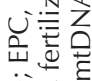

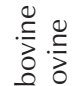

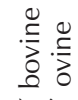

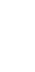

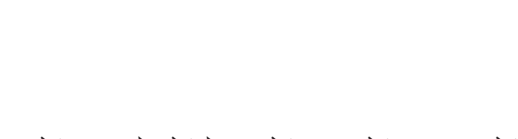

这这苛

$\frac{m}{\frac{0}{0}}$

뚠

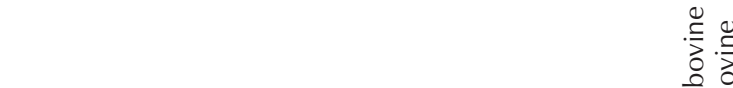

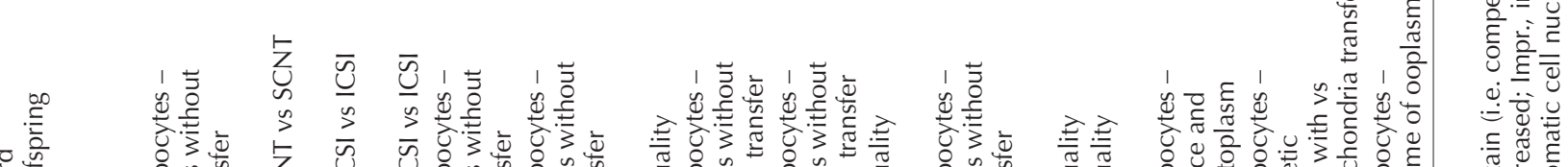
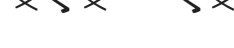

才己

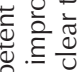

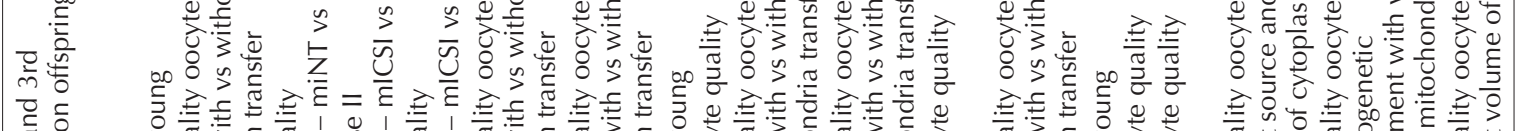




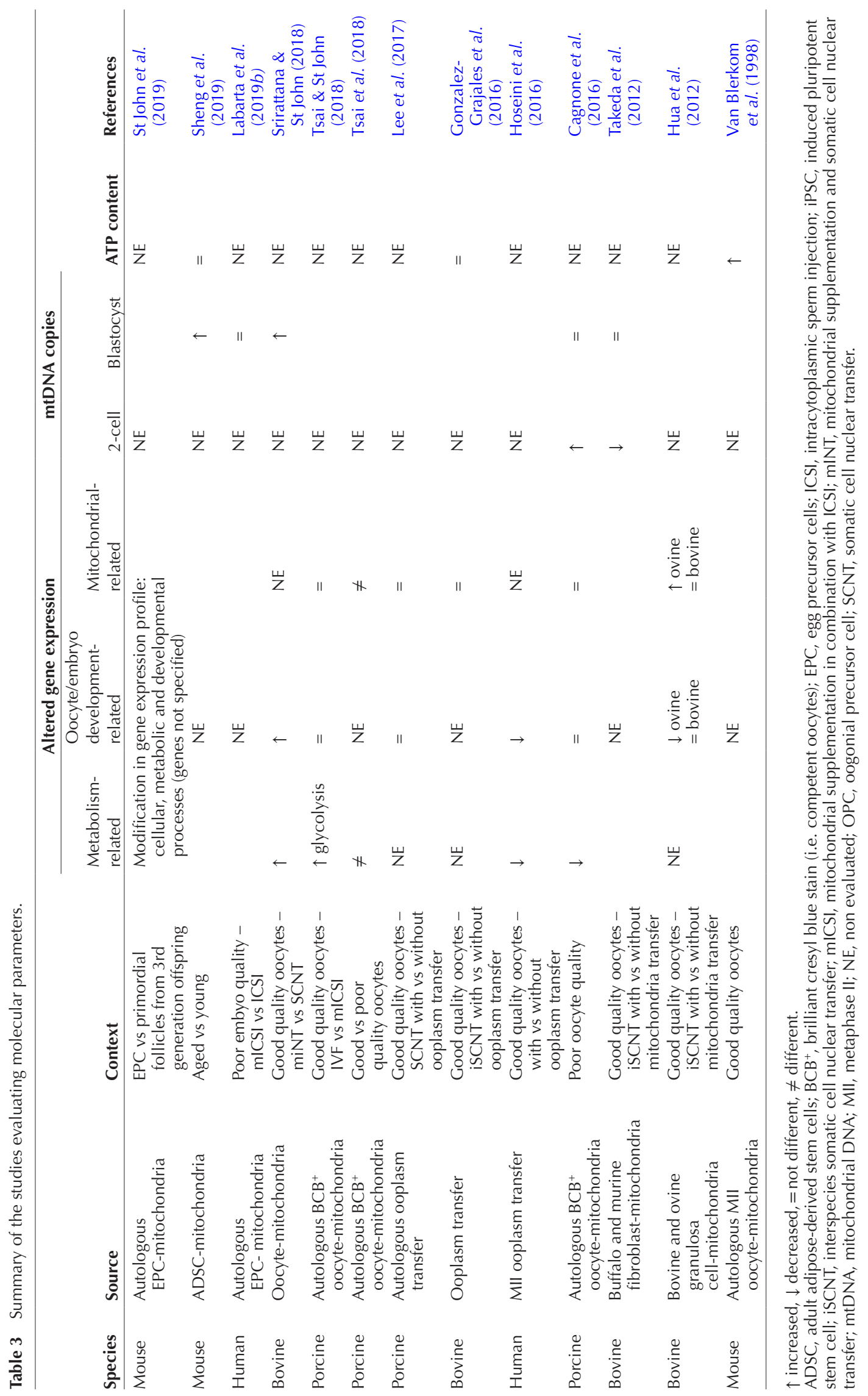


14/25 women in AUGMENT groups vs 2/25 women in ICSI group). Oocytes were not randomly assigned to each group, nor was the criterion for allocation defined (Fakih 2015). Finally, Oktay et al. (2015), reported a clinical pregnancy rate of $40 \%$ (4 out of 10 women) in comparison with the $10 \%$ baseline of this fertility center in Turkey, among couples with multiple IVF failures.

Other experimental studies with very small samples, again with controls being previous ART cycles, revealed a tendency toward improvement of clinical pregnancy rates after mitochondrial supplementation by ooplasmic transfer. In the study by Cohen et al. (1998), pregnancy was achieved in three out of five patients (18 embryo transfers) with no previous pregnancies (23 prior embryo transfers). In the study of Huang et al. (1999), pregnancy was achieved in four out of nine patients (39 embryo transfers) with no previous pregnancies (85 prior embryo transfers). In the study conducted by Lanzendorf et al. (1999), one out of four patients achieved a pregnancy, although comparisons with previous cycles were not reported. Successful pregnancies after ooplasmic transfer were reported in three publications in the context of aging (Kong et al. 2003) and poor embryo quality (Cohen et al. 1997, Dale et al. 2001).

To evaluate the safety of mitochondrial transfer information regarding genetic screening and newborn/ child follow-up was also assessed in the aforementioned studies and other clinical studies. Genetic screening was performed in five studies. Preimplantation genetic screening (PGS) revealed no differences in the euploid rate between the AUGMENT group and control group $(43.8 \pm 41.7 \%$ vs $63.8 \pm 44.1 \%)$ in one study (Labarta et al. 2019b). The euploid embryo rate was 32\% in the AUGMENT group in another study (Oktay et al. 2015). Karyotype (determined after amniocentesis) was normal in all the fetuses of ongoing pregnancies in three other studies (Cohen et al. 1997, 1998, Huang et al. 1999).

Cohen and coworkers (Cohen et al. 1998, Brenner et al. 2000, Barritt et al. 2001b) investigated the pattern of mitochondrial inheritance in the cases of ooplasmic transplantation performed in their laboratory. Their technique involved the transfer of ooplasm from a young donor to a recipient oocyte and therefore, the infusion of a different mtDNA population. mtDNA heteroplasmy was confirmed by mtDNA fingerprinting in samples from embryos (46\%), amniocytes (25\%), placentas $(50 \%)$, fetal cord blood $(50 \%)$ and the blood of two 1-year old children (100\%). One of the two babies with mitochondrial heteroplasmy in cord blood was described as healthy at a 6-month follow-up while there was no information on the other. The two 1-year old children were reported as healthy.

A total of 22 healthy infants born after mitochondrial supplementation (14 after allogenic ooplasm) were reported. Despite the presence of heteroplasmy, a normal healthy child reaching appropriate developmental milestones was reported at 6 -month pediatric evaluation by Brenner et al. (2000). Sixth month follow-up was also carried out in the study from Labarta et al. (2019b), reporting the absence of congenital malformations, although this study lacks detailed information on how the follow-up had been conducted. Follow-up was not performed after birth in the remaining children.

Some abnormalities could be missed and only diagnosed after the 6-month follow-up period. However, major congenital abnormalities are often diagnosed in prenatal or neonatal period and various pathologies are multifactorial so it would be difficult to associate these abnormalities to the technique.

\section{Fertilization rate and embryo development}

Fertilization rate in mitochondrial supplementation group was higher than in control group in 9 out of 25 studies (Cohen et al. 1998, El Shourbagy et al. 2006, Yi et al. 2007, Chiaratti et al. 2011, Hua et al. 2012, Oktay et al. 2015, Cagnone et al. 2016, Wang et al. 2017b, $\mathrm{Xu}$ et al. 2019). This rate was not significantly different in 16 studies (Huang et al. 1999, Lanzendorf et al. 1999, Nagai et al. 2004, Takeda et al. 2005, Van Thuan et al. 2006, Hua et al. 2007, Sansinena et al. 2011, Takeda et al. 2012, Gonzalez-Grajales et al. 2016, Igarashi et al. 2016, Lee et al. 2017, Li et al. 2017, Srirattana \& St John 2018, Sheng et al. 2019), and was not evaluated in the remaining studies (Petr et al. 1994, Cohen et al. 1997, Van Blerkom et al. 1998, Brenner et al. 2000, Barritt et al. 2001b, Dale et al. 2001, Kong et al. 2003, Hoseini et al. 2016, Tsai \& St John 2018, Tsai et al. 2018, St John et al. 2019).

Improved embryo development was reported in 12 out of 27 papers (Cohen et al. 1997, 1998, Dale et al. 2001, El Shourbagy et al. 2006, Hua et al. 2007, Yi et al. 2007, Chiaratti et al. 2011, Hua et al. 2012, Cagnone et al. 2016, Wang et al. 2017b, Xu et al. 2019). Embryo development was not different from controls in 15 studies (Huang et al. 1999, Lanzendorf et al. 1999, Nagai et al. 2004, Takeda et al. 2005, Van Thuan et al. 2006, Sansinena et al. 2011, Takeda et al. 2012, Oktay et al. 2015, Gonzalez-Grajales et al. 2016, Igarashi et al. 2016, Lee et al. 2017, Li et al. 2017, Srirattana \& St John 2018, Labarta et al. 2019b, Sheng et al. 2019) and was not evaluated in the remaining (Petr et al. 1994, Van Blerkom et al. 1998, Brenner et al. 2000, Barritt et al. 2001b, Kong et al. 2003, Hoseini et al. 2016, Tsai \& St John 2018, Tsai et al. 2018, St John et al. 2019). Although not significant, one study reported a trend toward higher embryo grade on day 3 (Oktay et al. 2015).

One of the studies did not evaluate fertilization or embryo development, and therefore was not included in Table 1. However, it was not excluded from our review since it demonstrates that the microinjection of 
cytoplasm from fully grown oocytes can induce germinal vesical breakdown in immature oocytes (Petr et al. 1994), a finding that supports the improvement of oocyte competence with mitochondrial supplementation.

\section{Pregnancy and offspring from animal studies}

Pregnancy and the offspring were monitored in four of the animal studies, two of them reporting an improvement in pregnancy rates following mitochondria/ooplasmic transfer. Chiaratti et al. demonstrated the efficacy of ooplasmic transfer to rescue bovine oocytes exposed to ethidium bromide, an inhibitor of mtDNA replication and transcription. Blastocyst from the two groups supplemented with ooplasm (ethidium bromide and control) were transferred to recipient cows. The group exposed to ethidium bromide had a gestation rate of $32 \%$ compared to $17 \%$ of control group (good-quality oocytes not exposed to ethidium bromide). Three calves were born following ooplasmic transfer and were normal (Chiaratti et al. 2011).

Mouse oocytes were injected with autologous mitochondria from adipose tissue-derived stem cells (ADSC) in the other study (Wang et al. 2017b) reporting an improvement in pregnancy rate. The authors compared ICSI with (experimental group) and without mitochondrial supplementation (control group) in mature oocytes from reproductive aged mice (12 months-old) and concluded that the procedure had rescued fertility based on the live-pup rate of $15,7 \%$ vs $2 \%$. The study reports the birth of eight mouse pups in the mitochondria transfer group (transfer of 51 embryos to 9 recipient) compared to one pup (transfer of 50 embryos to 7 recipient) in the control group. Data on embryo development and pregnancy rates from young mice after ICSI was not available, neither was a comparison between oocytes from young and aged mice, although the very low pup live birth reported in both experimental and control group is noteworthy.

The other two papers reported no improvement in implantation rate ( $\mathrm{Li}$ et al. 2017) or birth rates (Van Thuan et al. 2006). In the study from Li et al. (2017), mouse zygotes retrieved from the ampulla of the oviducts were injected with either mitochondria from induced pluripotent stem cell (iPSC) or mitochondrial respiration buffer (control group). They were then transferred into surrogate mice and excised at embryonic day 13.5 to compare placental and fetal weights, which were similar. On the other hand, Van Thuan et al. (2006) described opposite results, obtaining higher placental weights and fetal deaths in the experimental group. However, a very different methodology was used in this study, seeking to determine the effects of cytoplasmic transfer from different mouse strains, different cell sources (cumulus and embryonic cells) and different volumes into mouse oocytes.
A higher degree of embryo mitochondrial heteroplasmy was found in two-cell to blastocyst stage embryos and related to embryo arrest (Hua et al. 2012). However, it is important to mention that these results were observed in the context of interspecies somatic cell nuclear transfer (iSCNT). Cloned embryos were produced using bovine oocytes as the recipient cytoplasm and ovine granulosa cells as the donor nuclei, supplemented with bovine (BOBMT embryos) or ovine (BOOMT embryos) mitochondria. The degree of heteroplasmy was calculated as the percentage of bovine mtDNA copy number divided by ovine mtDNA copy number. BOOMT embryos had a higher degree of mitochondrial heteroplasmy and a significantly lower developmental rate in comparison to control group (cloned embryos without supplemented mitochondria). In contrast, the degree of heteroplasmy and developmental rate of BOBMT embryos were not different from controls.

Donor mtDNA was present in mouse placentas and fetuses after supplementation with mitochondria from iPSC. In this study (Li et al. 2017) similar patterns of methylation patterns in the differentially methylated regions (DMRS) of $\mathrm{H} 19$ and SNRPN, responsible for embryo development, were observed between embryos from experimental (iPSC) and control groups. Takeda et al. (2012) described no differences in mtDNA content between bovine blastocysts produced after injection of water buffalo mitochondria and controls (injected with buffer or uninjected). Also, parthenogenetic activation to the blastocyst stage was achieved. These findings indicate that intergeneric mitochondria were not destroyed and heteroplasmy did not apparently compromise embryo development. Mitochondrial heteroplasmy was also found in the three calves born after ooplasmic transfer and, as mentioned before, the two gestation had developed to term and the three calves were described to be healthy at birth (Chiaratti et al. 2011).

In addition to previous studies, the safety of mitochondrial transfer was investigated not only in the first but in three generations of offspring by St. John et al. (2019). Autologous egg precursor cell (EPC)mitochondria were transferred to mouse oocytes and resulted in the birth of seven female founders. When these females reached sexual maturity they were mated, and the offspring formed the first generation. The cycle was repeated until the third generation. Physiological and anatomical evaluation were performed in all three generations. F1 mitochondrial supplemented mice were found to be heavier than controls during the first 3 weeks of life, but no differences were found in subsequent generations. In addition to minor anomalies, the authors observed cardiac valvular pathology in all three of the first-generation mice and in one from the second generation. This cardiac defect was not observed in the third-generation or in control mice. 


\section{Gene expression, mitochondrial DNA copy number and ATP content}

There were 13/36 studies assessing molecular outcomes in which two used human cells (Hoseini et al. 2016, Labarta et al. 2019b) while the others different animal models such as mouse (Van Blerkom et al. 1998, Sheng et al. 2019, St John et al. 2019), bovine (Hua et al. 2012, Takeda et al. 2012, GonzalezGrajales et al. 2016, Srirattana \& St John 2018) or porcine (Cagnone et al. 2016, Tsai \& St John 2018, Tsai et al. 2018). The expression of genes related to metabolism, oocyte/embryo development and mitochondria evaluated in these studies was analyzed and summarized (Table 3).

Upregulated metabolism-related genes were reported in two studies although regulating different processes. ATP5B and ATP1A1, which are involved in oxidative phosphorylation (OXPHOS), were upregulated in mINT (mitochondrial supplementation and somatic cell nuclear transfer)-derived embryos (Srirattana \& St John 2018) while triosephosphate isomerase 1 (TPI1) and glyceraldehyde-3-phosphate dehydrogenase (GAPDH), key genes in the glycolysis pathway, were significantly higher in embryos derived from mitochondrial transfer when compared to stage-matched IVF embryos (Tsai \& St John 2018). However, another study from the same group showed that blastocyst stage gene expression is altered by supplementation of mtDNA-deficient oocytes. Specifically, metabolism and mitochondrial-related genes, such as COMMD4 (COMM domain containing 4) (Tsai et al. 2018). Furthermore, energy-producing gene ATPase6 was also downregulated (Hoseini et al. 2016).

BCB (Brilliant Cresyl Blue) has been used in mammalian species to assess developmental competence. This dye is reduced to a colorless compound by glucose-6-phosphate dehydrogenase (G6PD). Since G6PD is progressively downregulated during oocyte growth, good-quality oocytes stain blue $\left(\mathrm{BCB}^{+}\right)$while developmentally incompetent oocytes are colorless $\left(\mathrm{BCB}^{-}\right)$. Although mICSI-BCB- blastocysts had gene expression patterns more similar to ICSI $\mathrm{BCB}^{+}$blastocyst than ICSI BCB', which supports a stabilization effect of mitochondrial supplementation, $\mathrm{BCB}^{-}$blastocysts showed downregulated expression patterns (DEG), particularly in metabolism-related genes. Interestingly, a pathway that regulates mitochondrial biogenesis (involving sirtuins) was activated (Cagnone et al. 2016).

Concerning oocyte and embryo development related genes, no differences in pluripotency genes, such as OCT4 and SOX2, were reported (Hua et al. 2012, Cagnone et al. 2016, Lee et al. 2017, Tsai \& St John 2018). Srirattana and St John (2018) found that 188 differentially expressed genes (DEGs) were upregulated and 321 DEGs were downregulated in the miNT blastocysts, being cellular development the most influenced molecular and cellular function, with increased expression. On the contrary, when cytoplasmic transfer from human MII (metaphase II stage) oocytes into GV (germinal vesicle stage) oocytes was performed, genes involved in cytoplasmic maturity (GDF9, BMP15), meiosis (CDC25, AURKC), spindle check point (BUB1, CDC20, MAD2L1), DNA repairing and cell cycle checkpoint enzymes (ATR, ATM, BRCA1) were not expressed (Hoseini et al. 2016).

Mitochondrial transcription factor A (TFAM) was expressed in similar range in mitochondrial supplementation groups, as well as mitochondrial transcription factor B1 (TFB1), Sirtuins (Tsai \& St John 2018), POLRMT (Hua et al. 2012) and Mitochondrial Mitofusin-1 (Lee et al. 2017), indicating no differences concerning mitochondrial-related genes expression. However, another study demonstrated that oocytes supplemented with mitochondria modulated methylation of POLG (hypomethylation) at metaphase II oocytes, leading to mtDNA replication prior to implantation (Tsai et al. 2018).

St John et al. (2019), identified 53 differentially expressed genes between the primordial follicles of third-generation mice, indicating that mitochondrial supplementation at the time of fertilization may act on the germline to modify chromosomal gene expression. Indeed, using the Panther Ontology Classification System, the authors found that cellular, metabolic and developmental processes were the most modified biological processes, while binding, catalytic activity and receptor activity were the most modified molecular functions.

After autologous mitochondrial transfer no differences in mtDNA content were evident in AUGMENT euploid embryos (21.8 (IQR 14.6-24.7)) compared to control group (16.9 (IQR 13.8-23.9) (Labarta et al. 2019b). As mentioned before, both groups had similar fertilization and embryo development rates.

In mouse blastocysts mtDNA copy number was significantly higher in aged oocytes injected with mitochondria $(240,891 \pm 75,642, n=6)$ when compared with the buffer-injected group (41,228 \pm 5,019, $n=6$ ) (Sheng et al. 2019). Similarly, in bovine, additional mitochondrial injection significantly increased mtDNA copy number in blastocyst stage embryos (Srirattana \& St John 2018). However, none of these studies demonstrated better embryo development in association with higher mtDNA copy number.

Cagnone et al. (2016) measured mtDNA copy number in MIl oocytes, 2, 4, 6, 8 and 16-cell stage, morula, early blastocysts and expanded blastocysts, to monitor evolution through porcine embryo development. $\mathrm{BCB}^{+}-$ embryos (derived from developmentally competent oocytes) generated by IVF or ICSI demonstrated a similar profile, showing a decrease from MII oocytes to 2-cell embryos, the same content during preimplantation development and an increase at the expanded blastocyst stage. On the contrary, embryos derived from 
compromised oocytes (BCB-) and generated by ICSI had lower mtDNA at the MII stage, a turnover at the 4-cell stage and hereafter, reflecting mitochondrial replication before the expanded blastocyst stage. Embryos derived from compromised oocytes $\left(\mathrm{BCB}^{-}\right)$and generated by $\mathrm{mICSI}$ had higher but persistent levels of mtDNA when compared to ICSI-BCB ${ }^{-}$. All groups had similar mtDNA copy numbers $(>200,000)$ at expanded blastocyst. This study demonstrated that oocyte supplementation with mitochondria is associated with maintaining a higher mtDNA copy number in preimplantation embryos, higher fertilization rates and better embryo development. Also, low levels of mtDNA copy number in embryos derived from compromised oocytes could activate premature mitochondrial replication (e.g. before expanded blastocyst stage) as a compensatory mechanism.

Finally, only one out of the three studies that determined ATP production after mitochondrial supplementation using a bioluminescence assay demonstrated an increase in net ATP production in recipient oocytes (Van Blerkom et al. 1998), while the others found no differences (Gonzalez-Grajales et al. 2016, Sheng et al. 2019).

\section{Discussion}

Although there has been some experimental effort in this matter, this systematic review demonstrated insufficient evidence to conclude on the efficacy of mitochondrial supplementation to enhance oocyte competence. In fact, we identified 36 papers addressing the efficacy and safety of mitochondrial supplementation, most of them from basic research. Clinical studies were found lacking, because of the type of studies (only one RCT) and the small sample size (majority of studies with less than 10 patients). The conclusions of our systematic review cannot overlook therefore what we consider to be substandard evidence-based research. Moreover, the diversity of methodological approaches and contradictory results hampers the organization of data extracted from analyzed studies.

The need of further well-designed studies on this issue in both pre-clinical and clinical research is evident, and a more detailed discussion of different aspects uncovered in this review may be useful in helping to explore different aspects in future studies.

\section{On the source of mitochondria for supplementation}

The only clinical trials evaluating the effect of mitochondrial transfer were performed with autologous mitochondria isolated from cells - oogonial germline stem cells (OSC) (Fakih 2015, Oktay et al. 2015, Labarta et al. 2019b), the existence of which is still controversial (Gosden 2004, Bristol-Gould et al. 2006, Zhang et al. 2014, Gosden \& Johnson 2016). Indeed, the identification of OSC from ovarian cortex biopsies of human and other species have not been replicated by other groups (Liu et al. 2007, Lei \& Spradling 2013, Yuan et al. 2013) and detailed information on the protocol for identifying and harvesting these cells is lacking. A rare and mitotically active pool of cells has been purified from the ovarian cortex of reproductiveaged women, considered to be germline stem cells (White et al. 2012). However, the method used to identify these cells, the human Vasa analog - DDX4 antibody, has been shown to label other non-mitotically active cells in postnatal ovaries (Zhang et al. 2012).

Evidence against neo-oogenesis does not exclude the possibility of the survival of a population of stem cells (or stem cell-like cells) of uncertain potency that could be harvested from ovarian cortex. Still, considering the lack of specificity of DDX4 and scarcity of the alleged OSC population in adult ovarian tissue, these cells were surprisingly identified in all except one biopsy (total of 57 biopsies including three fragments of the ovarian cortex) in the study conducted by Labarta et al. (2019b). In addition, the quantity of mtDNA that is actually transferred into oocytes is not described in any of the AUGMENT studies (Fakih 2015, Oktay et al. 2015, Labarta et al. 2019b), but is expectably lower than the content found in most somatic cells, probably ranging from 10-100 copies considering the homology with oogonia and primordial germ cells (Shoubridge \& Wai 2007). These facts support the conclusion that injected mitochondria do not modify the dynamics of mtDNA content in blastocysts, inferred by the similar mtDNA content found in blastocysts from AUGMENT and control groups (Labarta et al. 2019b). To better understand if injected mitochondria are destroyed or not replicated it would be important to quantify or evaluate the viability of isolated mitochondria, as well as to label and track mitochondria after injection.

The clinical use of OSC in women with advanced maternal age is also an issue because the intraovarian environment may become inadequate for OSCs differentiation (Wang et al. 2017a). Another aspect questioning the feasibility of the AUGMENT studies is the high cost and invasive method necessary for cell recovery. This method involves a surgery and it is noteworthy to mention the risk of diminishing the ovarian reserve. Thus, the invasiveness of the procedure, the controversial existence of OSC and the uncertainty about the number and quality of isolated mitochondria extracted from OSC are some of the issues pointed out by authors concerning the AUGMENT technology (Gosden \& Johnson 2016, Kristensen et al. 2017, Cecchino et al. 2018, Labarta et al. 2019a, Qi et al. 2019).

Regardless, germline or oocyte-differentiated cells are advocated (Schatten et al. 2014, Darbandi et al. 2016) as a privileged source of mitochondria for oocyte transfer because of mitochondrial dependency on the nuclear 
genome. However, our review shows that other sources of mitochondria such as hepatocytes (Yi et al. 2007) and granulosa cells (Hua et al. 2007) have shown promising results, questioning this preference. Indeed, labeled granulosa cell-mitochondria were identified up to the hatched blastocyst stage in bovine embryos (Hua et al. 2007) and found to improve embryo development and clinical pregnancy. A higher oxygen consumption rate was observed in oocytes from aged mice after injection of mitochondria from liver cells (Igarashi et al. 2016). However, it is unclear how nuclear genome interacts with the extra mtDNA that is supplemented.

Mitochondria obtained from granulosa or cumulus cells have, in theory, a great disadvantage as a mitochondrial source since these cells are also affected by aging (May-Panloup et al. 2016). Granulosa cells of advanced maternal age women have been shown to contain more mtDNA mutations (Seifer et al. 2002, Tsai et al. 2010) and damaged mitochondria (Tatone \& Amicarelli 2013, Liu et al. 2017).

The use of stem cells (e.g. hematopoietic and adiposederived stem cells) as the source of mitochondria is encouraged by many authors (Schatten et al. 2014, Labarta et al. 2019a) due to the mitochondrial morphological and metabolic similarities with mitochondria in metaphase II oocytes. Indeed, preovulatory secondary oocytes display round-shaped mitochondria and an electron-dense matrix. After fertilization, mitochondrial structure and metabolism are in line with that of somatic cells. Mitochondria acquire an elongated form with many cristae, and gradually changes from glycolysis to OXPHOS (Motta et al. 2000, Eichenlaub-Ritter et al. 2011).

An alternative source, not yet explored, was proposed by Kristensen et al. The authors pointed out that OSC do not pass through the mitochondrial genetic bottleneck (important for selection of subpopulations of mtDNA during oogenesis) and suggested a possible increase in the supply of fully grown oocytes by two methods: in vitro maturation of immature oocytes collected from women undergoing ART or in vitro activation of ovarian cortical biopsies (Kristensen et al. 2017).

The transfer of oosplasm from a young donor has proven efficient in both animal and human studies, resulting in the birth of nearly 30 apparently healthy babies worldwide (Barritt et al. 2001a). Safety is the main disadvantage of this procedure, due to the transfer of foreign populations of mtDNA (addressed ahead), but there is sufficient evidence to suggest that mitochondria are potentially responsible for the improvements of oocyte quality that have been reported. This is based on the demonstrated mitochondrial role in oocyte competence acquisition and embryonic development (Benkhalifa et al. 2014, May-Panloup et al. 2016, Cecchino et al. 2018). Spindle formation is critical for normal chromosome segregation and dependent on mitochondrial ATP supply. Sufficient mitochondria are necessary for the rise in ATP production observed during mitochondria assemble around the spindle in meiosis I and II. Viable mitochondria are also necessary for calcium signaling at the oolemma after sperm entry as it allows the oocyte progression to anaphase and resumption of meiosis II (Eichenlaub-Ritter et al. 2011). Other strategies to improve oocyte competence in the context of aging also rely on increasing mitochondrial biogenesis and activity, without the need for oocyte mitochondrial injection. Resveratrol acts through sirtuin pathway and Coenzyme $\mathrm{Q}_{10}$ contributes to the transport of electrons in the mitochondrial respiratory chain. Both these pharmacological agents were able to enhance embryonic development in animal models of ovarian aging (Schatten et al. 2014, Darbandi et al. 2016, MayPanloup et al. 2016).

In summary, there is still no evidence to support a particular type of cell as the optimal source of mitochondria for oocyte supplementation. What we can conclude is that injected mitochondria must be from the same women (autologous source) and without the same age-related alterations as those found in oocytes (such as mtDNA mutations and mitochondrial dysfunction). Apart from the type of cell source, recover of healthy mitochondria is of utmost importance in the process of mitochondrial isolation. This usually encompasses centrifugation and homogenization steps. Failure to achieve good results after oocyte mitochondrial supplementation might be attributed, for instance, to the presence of cell debris that may cause metabolic overload in poor quality oocytes (Qi et al. 2019).

Furthermore, the viability of isolated mitochondria should be demonstrated prior to oocyte injection. In our review, none of the human studies, and only a few animal studies (Hua et al. 2012, Cagnone et al. 2016, Sheng et al. 2019), evaluated the function of isolated mitochondria prior to supplementation. Likewise, as mentioned before, it would be important to label and track mitochondria during preimplantation development.

\section{On the experimental or clinical context}

The studies investigating the efficacy of oocyte mitochondrial supplementation were performed using different species (human, mouse, bovine and porcine), different assisted reproduction techniques (fertilization, SCNT, parthenogenesis) in a set of different contexts, such as IVF failure, aging and poor oocyte or embryo quality. Curiously, this technique was also tested in good quality oocytes by many authors.

Intriguingly, although there is an ongoing debate on using mitochondria as an oocyte rejuvenation tool (Igarashi etal. 2015, Labarta etal. 2019a, Mobarak et al. 2019), none of the recent clinical studies evaluated the effect of mitochondrial transfer in oocytes of advanced maternal age. Aging was only addressed in one case 
report (Kong et al. 2003) and in a very small sample $(n=4)$ study conducted in 1999, aiming to evaluate the effects of ooplasm transfer (Lanzendorf et al. 1999).

Oocytes from women with advanced maternal age have lower copies of mtDNA (May-Panloup et al. 2005, Duran et al. 2011). Furthermore, the rate of mtDNA mutations is approximately 15 times higher that of the nucleargenome, probably explained by theproximity with the respiratory chain and the lack of histones and repair enzymes (May-Panloup et al. 2016, Reznichenko et al. 2016). Although controversial, a great number of mtDNA abnormalities has been reported in oocytes from women over 35 years of age (Chan et al. 2005), and the higher rate of mutations represents a plausible explanation for this finding. In addition, ovarian aging is associated with mitochondrial dysfunction. Age-related modifications include mitochondrial morphologic changes, different distribution patterns, lower ATP production, lower membrane potential and higher reactive oxygen species (ROS) production (EichenlaubRitter et al. 2011, Qiao et al. 2014, May-Panloup et al. 2016). In addition, genes related to mitochondrial function are downregulated in oocytes from older women (Steuerwald et al. 2007). Therefore, it seems logical to introduce new good-quality mitochondria into oocytes of advanced maternal age women.

Lower copies of mtDNA were also found in oocytes from women with poor-quality oocyte (not age-related), and this was associated with lower fertilization rates (Reynier et al. 2001, Santos et al. 2006). Therefore, it also seems logical to test the efficacy of mitochondrial supplementation in couples with multiple IVF failures. The AUGMENT treatment had apparent good results in the first clinical trials performed (Fakih 2015, Oktay et al. 2015) but concerns were raised about the methodology of these studies, such as the risk of bias introduced by IVF intercycle variability (Cozzolino et al. 2019, Labarta et al. 2019b). These flaws were clarified with the RCT from Labarta et al. (2019b) demonstrating no benefit of using mitochondrial oocyte supplementation from OSC. While the group from IVI-RMA in Spain disproved the efficiency of the AUGMENT treatment (Labarta et al. 2019a), there is still one clinical trial in progress (ClinicalTrials.gov) (ClinicalTrials.gov known as a database of general and private clinical studies that have been conducted around the world and a clinical studies source founded by the United States NLM (National Library of Medicine).) employing this treatment.

In terms of animal models, most of the studies have compared mitochondrial transfer with IVF and ICSI (both as control groups) in oocytes with presumably normal mitochondrial function and content. Testing the efficacy of mitochondrial supplementation in goodquality oocytes may be problematic for two reasons. First, as already mentioned, the rationale to supplement oocytes with mitochondria is based on a strong body of the evidence that low quality oocytes and/or poor embryo development have fewer mtDNA copies (Reynier et al. 2001, Chan et al. 2005, Santos et al. 2006, Murakoshi et al. 2013, Fragouli et al. 2015) as well as reduced metabolic activity, low ATP content and mitochondrial dysfunction (Eichenlaub-Ritter et al. 2011, Benkhalifa et al. 2014, Schatten et al. 2014, MayPanloup et al. 2016). Second, it has been stated that IVF is a more efficient reproductive technique compared to ICSI concerning in vitro production of embryos in farm animals (Betteridge 2006, Knox 2014) since it requires less manipulation and causes less mechanical damage in oocytes (Schultz \& Williams 2002). Additionally, studies in animals showed that fertilization by ICSI cause alterations in the transcriptome of the developing embryo (Giritharan et al. 2010) and may induce a delay in preimplantation embryo cleavage (Dumoulin et al. 2000). Thus, the benefits of mitochondrial transfer should be tested in conditions of low mtDNA and/or mitochondrial dysfunction and the most suited control to mICSI injection should be ICSI and not IVF.

The purported aim of mitochondrial supplementation at the time of fertilization is to increase the amount of mtDNA available to support embryo development until replication resumes. However, two of the analyzed studies have failed to demonstrate a better embryo development despite the higher mtDNA copies at blastocyst stage (Srirattana \& St John 2018, Sheng et al. 2019).

Although an increase in mitochondrial content was demonstrated, the viability of mitochondria after transfer was not evaluated and the energy supplied may have been insufficient for the energy demand, which is in agreement with the similar ATP content observed in blastocysts from mitochondria-injection group and control group (Sheng et al. 2019). Accordingly, additional mtDNA copies lead to an increase in the expression of genes involved in the glycolytic metabolism and embryonic development, indicating a state of readiness to promote cellular proliferation, which shows that the mitochondrial and nuclear genomes interact to promote embryonic development (Srirattana \& St John 2018).

Oocyte mitochondrial content is distributed to daughter cells during early embryogenesis. Blastomeres will depend on these mitochondria to cell function until resumption of mitochondrial replication, that is thought to occur around the time of implantation, at the expanded blastocyst stage in human (Hashimoto et al. 2017), bovine (Hendriks et al. 2019) and porcine (Cagnone et al. 2016) and E6 day in mouse (FacuchoOliveira et al. 2007). In line with oocyte, embryo mtDNA copies would be expected to reflect embryo quality. Indeed, low levels of mtDNA were found in uncleaved embryos (Murakoshi et al. 2013). However, the role of mtDNA as a biomarker of viability seems to be more complex.

Klimczac et al. could not demonstrate a relationship between mtDNA content and blastocyst morphology 
and implantation potential after evaluation of human euploid embryos (Klimczak et al. 2018). On the other hand, higher mtDNA copies have been associated with poor implantation potential in human embryos. This association was perceived in both day 3 and blastocyst embryos (Diez-Juan et al. 2015). These findings have been reproduced by another group (Fragouli et al. 2015) with some disparities. Fragouli et al. also reported a low implantation potential in blastocysts with unusually high mtDNA levels (above a threshold). The authors evaluated mtDNA copies according to women's age and found high levels of mtDNA in blastocysts from older women (38-42 years old) when compared to younger women (29-37 years old). However, opposite results were found in cleavage stage embryos, with higher mtDNA levels in young women and lower mtDNA levels in older women. A suggestion to explain this paradox was proposed by the authors, in which mitochondrial replication would occur before the blastocyst stage in older women (Fragouli et al. 2015). In addition, it has been proposed that mitochondrial proliferation can be a compensatory mechanism for mitochondrial insufficiency, leading to oxidative damage and dysregulation of pathways involving mitochondria (May-Panloup et al. 2016).

Therefore, higher levels of mtDNA in preimplantation embryos, as seen in ICSI BCB- (derived from developmentally incompetent oocytes) porcine embryos (Cagnone et al. 2016) and aged mouse (mitochondriainjected) embryos (Sheng et al. 2019), compared to matched good-quality embryos, may indicate premature mitochondrial replication.

Although premature mitochondrial replication could potentially indicate poor embryo quality, the clinical value of using quantitative mtDNA for assessing blastocyst viability still needs to be explored.

Apart, these results support the importance of a sufficient oocyte mitochondrial content before fertilization to allow normal embryonic development. Also, equal expression of mitochondrial-related genes (such as TFAM) in mICSI-BCB- compared to ICSI BCB+ (derived from competent oocytes) blastocysts also supports a stabilization effect of mitochondrial transfer, without compensatory mitochondrial proliferation activation.

\section{On treatment safety}

None of the studies included in this review reported cases of congenital malformations or chromosomal abnormalities, neither in ooplasmic nor mitochondrial transfer. Though, it is not clear from studies if miscarriages and stillbirths were systematically screened for congenital malformations that could have potentially been induced by epigenetic modifications.

In the context of ooplasmic transplantation, Cohen and coworkers reported two cases of abnormal 45, X fetuses (Barritt et al. 2001a). One was a spontaneous first-trimester miscarriage and the other a termination of pregnancy at 16 weeks. A pervasive developmental syndrome in a 5 -year-old child has also been reported (Labarta et al. 2019b). The ooplasm is highly structured, thus subtle problems might well arise if the maturation of the donating oocyte is not in perfect synchrony with the recipient oocyte. Although the number of successful pregnancies achieved following ooplasmic donation is too small to allow any meaningful interpretation, the genetic abnormalities reported raised safety concerns regarding mitochondrial heteroplasmy. Mixing two entities (ooplasm from donor and recipient) could influence the balance of pro-apoptotic and antiapoptotic factors, affect proteins closely linked to microtubule dynamics, such as mitogen-associated protein (MAPK) and M-phase promoting factor (MPF), modify DNA methylation and disturb mRNA translation (Darbandi et al. 2017). The major concern relates to the possible incompatibility between nuclear and mitochondrial genomes. Indeed, Hua et al. have demonstrated significant alterations in the expression of pluripotency and mitochondrial-related genes in association with mitochondrial heteroplasmy (Hua et al. 2012). Conversely, mtDNA heteroplasmy seems to be common in the general population (May-Panloup et al. 2016) and several murine studies failed to demonstrate mitonuclear incompatibility (Reznichenko et al. 2016).

The studies analyzed in our review confirmed the presence of donor mtDNA in the offspring with no apparent adverse effects on their development, although few tissues have been analyzed. The degree of heteroplasmy may be more relevant in organs/systems that are more dependent on mitochondrial activity and ATP production by oxidative phosphorylation, and that may therefore be more affected by any changes at this level (such as the heart muscle). This issue remains to be investigated in greater detail.

The euploid rate and the absence of reported congenital malformation from the clinical studies are reassuring. Animal research also favors the safety of the technique in that offspring was normal in all except one of the animal studies (Van Thuan et al. 2006, Chiaratti et al. 2011, Li et al. 2017, Wang et al. 2017b) and, as mentioned before, the fetal deaths reported derived from a study using different strains, different sources (cumulus and embryonic cells) and different volumes into mouse oocytes (Van Thuan et al. 2006).

Although unrelated to mitochondrial heteroplasmy, the safety of mitochondrial transfer from an autologous source is still a concern, considering the specificities of the morphologic and bioenergetic profile of mitochondria between oocytes and donor cells.

Oocyte maturation is characterized by a notorious increase in mitochondrial number accompanied also by a shift in mitochondria structure, suggesting functional differentiation. Oocytes from preantral follicles contain about 10,000 mitochondria with many cristae and light 
matrix, while oocytes from preovulatory follicles have about 100,000 round-shaped mitochondria with few cristae and dense matrix. In addition, the distribution of mitochondria also changes during oocyte maturation, from a homogeneous distribution to assembly close to the spindle and the oolemma, presumably for privileged energy supply. After fertilization, mitochondria acquire an elongated form with many cristae, and gradually changes from glycolysis to OXPHOS, although mitochondrial structure and function seem to be different in the two cell types (trophectoderm and inner cell mass) of preimplantation embryo. This shift from mainly glycolytic to OXPHOS is perceived in the trophectoderm, whereas the inner cell mass cells retains round-shaped mitochondria with few cristae (Motta et al. 2000, Eichenlaub-Ritter et al. 2011).

The dynamic balance among metabolic pathways (glycolysis and OXPHOS) has not only implications in energy supply but has also been implicated in cell regulation and apoptotic processes (Zhang et al. 2018, Rastogi et al. 2019). Therefore, the introduction of morphological and likely functionally different mitochondria into mature oocytes could induce mitochondrial reprogramming and adversely affect embryonic development. Mitochondria from somatic cells, such as GC/cumulus (Eichenlaub-Ritter et al. 2011) have been shown to have many cristae and a light matrix, features that are different from that of the mature oocyte. On the contrary, spherical mitochondria from stem cells are comparable to mature oocytes. Because of this morphological and metabolic (glycolytic) similarity, the use of mitochondria from stem cells have been encouraged by some authors (Schatten et al. 2014, Labarta et al. 2019a), as mentioned before.

Studies analyzed in our review have not explored metabolism-related gene expression in embryos derived from somatic cell mitochondrial supplementation. Gene expression from oocyte-mitochondria source have shown contradictory results, with increased expression of OXPHOS (Srirattana \& St John 2018) and glycolytic (Tsai \& St John 2018) pathways.

As mentioned, the coordinated expression of mitochondrial and nuclear-encoded genes is important to maintain the normal cellular function. Particularly, TFAM, which is involved in mtDNA stability, transcription and replication, seems to have an essential role in postimplantation embryos, leading to lethality in knockout TFAM mice (Ekstrand et al. 2004). Our review demonstrates a similar range of expression of TFAM in mitochondrial supplementation groups (Cagnone et al. 2016, Lee et al. 2017, Tsai \& St John 2018) even when granulosa cells were used as mitochondrial source (Hua et al. 2012). Also, no differences in pluripotency genes, such as OCT4 and SOX2, were reported in this study using somatic cellmitochondria, although these results were observed in the context of interspecies somatic cell nuclear transfer
(iSCNT). Likewise, our review has shown promising results in studies using hepatocytes (Yi et al. 2007) and granulosa cells (Hua et al. 2007) as somatic sources of mitochondria.

The possibility and consequences of mitochondrial reprogramming after oocyte supplementation with other (than oocyte) sources of mitochondria are still unclear and should be explored in further studies.

The possible association between mitochondrial transfer (from OSC) and cardiac defects raised by St. John et al. (2019) does not seem to be well-founded. The authors have suggested a link between mtDNA variants and heart defects, but the non-classified (insertion/ deletion at nt9821) and probably damaging (single nucleotide nt12581) variants were found in primordial follicles of the third-generation offspring, in which no heart defect was found. Moreover, the selection of mice for histopathological analysis and mtDNA sequencing was not clear, since out of the total mice from each generation only three were selected without randomization or a specific justification.

When considering epigenetic modifications, hypomethylation of the H19 and SNRPN differentially methylated regions (DMRS), have been associated with Silver-Russel syndrome and SNRPN gene may be implicated in Prader-Willi and Angelman syndromes. $\mathrm{Li}$ et al. have explored the methylation patterns of these genes, involved in embryo development, and found similar patterns, adding support to the safety of the procedure (Li et al. 2017), although more experimental data are needed.

\section{Conclusions}

Mitochondrial supplementation does not seem to cause harm although the benefit of improving oocyte competence is still unclear due to the diversity of methodological approaches and low-quality of the data available.

To the best of our knowledge, this is the first systematic review on the efficacy and safety of oocyte mitochondrial supplementation as a tool to improve oocyte quality and embryo development. Darbandi et al. (2016) reviewed ten different methods with the potential to increase mitochondrial activity in oocytes (including the transfer of mitochondria, mtDNA, ooplasm, nucleus, vectors, RNAs, proteins, dietary components), briefly summarizing the advantages and concerns of each technique. However, they did not analyze the efficacy and safety of each strategy, which are paramount toward validating this approach in clinical practice. A review on the efficacy and concerns of a particular strategy (ooplasmic transfer) was also performed by the same group (Darbandi et al. 2017).

It could be argued that a more complete analysis, such as a meta-analysis of human or animal studies, could have been even more informative. However, it 
would imply a more restrictive selection, and still be a challenge considering the great heterogeneity of studies in terms of the source of mitochondria (cytoplasm vs isolated mitochondria, allogenic vs autologous, type of cell used as a source), the different species and diverse contexts in which the procedure has been applied. Also, the high risk of bias would still weaken the conclusions.

There is a lack of strong evidence to advocate the application of mitochondrial supplementation in clinical practice, as a complementary treatment to ART. However, analyzed data support the need to investigate further, in both pre-clinical and clinical contexts. Given that mitochondria form a link between infertility and ovarian aging, women of advanced maternal age are the best candidates for the injection of healthy mitochondria. Therefore, future studies should explore the possibility of oocyte rejuvenation in the context of aging, using proper in vitro and in vivo models. Mitochondria should be obtained from an autologous source, ideally without the same age-related alterations as oocytes. Extraction and isolation process should be optimized to provide healthy and active mitochondria, ensuring viability prior to transfer, which should also be closely monitored. Furthermore, experimental groups should be compared to ICSI as a control, and not IVF. Also, significant efforts should be taken to explore the safety of the procedure prior to its application in clinical practice.

\section{Declaration of interest}

The authors declare that there is no conflict of interest that could be perceived as prejudicing the impartiality of the research reported.

\section{Funding}

Part of this work was financed by the European Regional Development Fund (ERDF) through the COMPETE 2020 - Operational Programme for Competitiveness and Internationalisation and Portuguese national funds via FCT Fundação para a Ciência e a Tecnologia, under the project UID/NEU/04539/2019. Additional funding was provided by the European Regional Development Fund (ERDF), through the Centro 2020 Regional Operational Programme: project CENTRO-01-0145-FEDER-000012-HealthyAging2020 (to M S and $\mathrm{S}$ R). The funding entities had no role in study design, data collection and analysis, decision to publish, or preparation of the manuscript.

\section{Author contribution statement}

A F F designed the study, performed the selection of studies and the extraction, analysis and interpretation of the data, and drafted the article. M S performed the selection of the studies and the extraction, analysis and interpretation of the data and drafted the article. S R performed the selection of the studies and the extraction and analysis of the data. J R S interpreted the data and revised the manuscript. A P S analyzed and interpreted the data and revised the manuscript. T A S interpreted the data and revised the manuscript. All authors read and approved the final version of the manuscript to be published.

\section{Acknowledgements}

The authors gratefully acknowledge the help provided by $\mathrm{Dr}$ Mariana Moura-Ramos for choosing the best tool to assess the quality of the studies included in this review.

\section{References}

Barritt J, Willadsen S, Brenner C \& Cohen J 2001a Cytoplasmic transfer in assisted reproduction. Human Reproduction Update 7 428-435. (https://doi.org/10.1093/humupd/7.4.428)

Barritt JA, Brenner CA, Malter HE \& Cohen J 2001b Mitochondria in human offspring derived from ooplasmic transplantation. Human Reproduction 16 513-516. (https://doi.org/10.1093/humrep/16.3.513)

Benkhalifa M, Ferreira YJ, Chahine H, Louanjli N, Miron P, Merviel P \& Copin H2014 Mitochondria: participation to infertility as source of energy and cause of senescence. International Journal of Biochemistry and Cell Biology 55 60-64. (https://doi.org/10.1016/j.biocel.2014.08.011)

Betteridge KJ 2006 Farm animal embryo technologies: achievements and perspectives. Theriogenology 65 905-913. (https://doi.org/10.1016/j. theriogenology.2005.09.005)

Brenner CA, Barritt JA, Willadsen S \& Cohen J 2000 Mitochondrial DNA heteroplasmy after human ooplasmic transplantation. Fertility and Sterility 74 573-578. (https://doi.org/10.1016/s0015-0282(00)00681-6)

Bristol-Gould SK, Kreeger PK, Selkirk CG, Kilen SM, Mayo KE, Shea LD \& Woodruff TK 2006 Fate of the initial follicle pool: empirical and mathematical evidence supporting its sufficiency for adult fertility. Developmental Biology 298 149-154. (https://doi.org/10.1016/j. ydbio.2006.06.023)

Cagnone GL, Tsai TS, Makanji Y, Matthews P, Gould J, Bonkowski MS, Elgass KD, Wong AS, Wu LE, Mckenzie M et al. 2016 Restoration of normal embryogenesis by mitochondrial supplementation in pig oocytes exhibiting mitochondrial DNA deficiency. Scientific Reports 623229. (https://doi.org/10.1038/srep23229)

Cecchino GN, Seli E, Alves Da Motta EL \& García-Velasco JA 2018 The role of mitochondrial activity in female fertility and assisted reproductive technologies: overview and current insights. Reproductive Biomedicine Online 36 686-697. (https://doi.org/10.1016/j.rbmo.2018.02.007)

Chan CC, Liu VW, Lau EY, Yeung WS, Ng EH \& Ho PC 2005 Mitochondrial DNA content and 4977 bp deletion in unfertilized oocytes. Molecular Human Reproduction 11 843-846. (https://doi.org/10.1093/molehr/ gah243)

Chiaratti MR, Ferreira CR, Perecin F, Meo SC, Sangalli JR, Mesquita LG, De Carvalho Balieiro JC, Smith LC, Garcia JM \& Meirelles FV 2011 Ooplast-mediated developmental rescue of bovine oocytes exposed to ethidium bromide. Reproductive Biomedicine Online 22 172-183. (https://doi.org/10.1016/j.rbmo.2010.10.011)

Cohen J, Scott R, Schimmel T, Levron J \& Willadsen S 1997 Birth of infant after transfer of anucleate donor oocyte cytoplasm into recipient eggs. Lancet 350 186-187. (https://doi.org/10.1016/S0140-6736(05)62353-7)

Cohen J, Scott R, Alikani M, Schimmel T, Munne S, Levron J, Wu L, Brenner C, Warner C \& Willadsen S 1998 Ooplasmic transfer in mature human oocytes. Molecular Human Reproduction 4 269-280. (https:// doi.org/10.1093/molehr/4.3.269)

Cozzolino M, Marin D \& Sisti G 2019 New Frontiers in IVF: mtDNA and autologous germline mitochondrial energy transfer. Reproductive Biology and Endocrinology 17 55. (https://doi.org/10.1186/s12958-0190501-z)

Dale B, Wilding M, Botta G, Rasile M, Marino M, Di Matteo L, De Placido G \& Izzo A 2001 Pregnancy after cytoplasmic transfer in a couple suffering from idiopathic infertility: case report. Human Reproduction 16 1469-1472. (https://doi.org/10.1093/humrep/16.7.1469)

Darbandi S, Darbandi M, Khorshid HR, Sadeghi MR, Al-Hasani S, Agarwal A, Shirazi A, Heidari M \& Akhondi MM 2016 Experimental 
strategies towards increasing intracellular mitochondrial activity in oocytes: a systematic review. Mitochondrion 30 8-17. (https://doi. org/10.1016/j.mito.2016.05.006)

Darbandi S, Darbandi M, Khorram Khorshid HR, Sadeghi MR, Agarwal A, Sengupta P, Al-Hasani S \& Akhondi MM 2017 Ooplasmic transfer in human oocytes: efficacy and concerns in assisted reproduction. Reproductive Biology and Endocrinology 15 77. (https://doi.org/10.1186/ s12958-017-0292-z)

Diez-Juan A, Rubio C, Marin C, Martinez S, Al-Asmar N, Riboldi M, Díaz-Gimeno P, Valbuena D \& Simón C 2015 Mitochondrial DNA content as a viability score in human euploid embryos: less is better. Fertility and Sterility 104 534.e1-541.e1. (https://doi.org/10.1016/j. fertnstert.2015.05.022)

Dumoulin JC, Coonen E, Bras M, Van Wissen LC, Ignoul-Vanvuchelen R, Bergers-Jansen JM, Derhaag JG, Geraedts JP \& Evers JL 2000 Comparison of in-vitro development of embryos originating from either conventional in-vitro fertilization or intracytoplasmic sperm injection. Human Reproduction 15 402-409. (https://doi.org/10.1093/ humrep/15.2.402)

Duran HE, Simsek-Duran F, Oehninger SC, Jones HW, Jr \& Castora FJ 2011 The association of reproductive senescence with mitochondrial quantity, function, and DNA integrity in human oocytes at different stages of maturation. Fertility and Sterility 96 384-388. (https://doi.org/10.1016/j. fertnstert.2011.05.056)

Eichenlaub-Ritter U 1998 Genetics of oocyte ageing. Maturitas 30 143-169. (https://doi.org/10.1016/s0378-5122(98)00070-x)

Eichenlaub-Ritter U, Wieczorek M, Luke S \& Seidel T 2011 Age related changes in mitochondrial function and new approaches to study redox regulation in mammalian oocytes in response to age or maturation conditions. Mitochondrion 11 783-796. (https://doi.org/10.1016/j. mito.2010.08.011)

Ekstrand MI, Falkenberg M, Rantanen A, Park CB, Gaspari M, Hultenby K, Rustin P, Gustafsson CM \& Larsson NG 2004 Mitochondrial transcription factor A regulates mtDNA copy number in mammals. Human Molecular Genetics 13 935-944. (https://doi.org/10.1093/hmg/ ddh109)

El Shourbagy SH, Spikings EC, Freitas M \& St John JC 2006 Mitochondria directly influence fertilisation outcome in the pig. Reproduction 131 233-245. (https://doi.org/10.1530/rep.1.00551)

Facucho-Oliveira JM, Alderson J, Spikings EC, Egginton S \& St John JC 2007 Mitochondrial DNA replication during differentiation of murine embryonic stem cells. Journal of Cell Science 120 4025-4034. (https:// doi.org/10.1242/jcs.016972)

Fakih MH, Shmoury ME, Szeptycki J, Dela Cruz DB, Lux C, Verjee S, Burgess CM, Cohn G \& Casper R 2015 The AUGMENTSM treatment: physician reported outcomes of the initial global patient experience. Journal of Fertilization: In Vitro, IVF-Worldwide, Reproductive Medicine, Genitics and Stem Cell Biology 3 154. (https://doi.org/10.4172/23754508.1000154)

Fragouli E, Spath K, Alfarawati S, Kaper F, Craig A, Michel CE, Kokocinski F, Cohen J, Munne S \& Wells D 2015 Altered levels of mitochondrial DNA are associated with female age, aneuploidy, and provide an independent measure of embryonic implantation potential. PLoS Genetics 11 e1005241. (https://doi.org/10.1371/journal.pgen.1005241)

Giritharan G, Li MW, Di Sebastiano F, Esteban FJ, Horcajadas JA, Lloyd KC, Donjacour A, Maltepe E \& Rinaudo PF 2010 Effect of ICSI on gene expression and development of mouse preimplantation embryos. Human Reproduction 25 3012-3024. (https://doi.org/10.1093/humrep/ deq266)

Gonzalez-Grajales LA, Favetta LA, King WA \& Mastromonaco GF 2016 Lack of effects of ooplasm transfer on early development of interspecies somatic cell nuclear transfer bison embryos. BMC Developmental Biology 16 36. (https://doi.org/10.1186/s12861-016-0137-6)

Gosden RG 2004 Germline stem cells in the postnatal ovary: is the ovary more like a testis? Human Reproduction Update 10 193-195. (https:// doi.org/10.1093/humupd/dmh023)

Gosden RG \& Johnson MH 2016 Can oocyte quality be augmented? Reproductive Biomedicine Online 32 551-555. (https://doi. org/10.1016/j.rbmo.2016.04.001)

Hashimoto S, Morimoto N, Yamanaka M, Matsumoto H, Yamochi T, Goto H, Inoue M, Nakaoka Y, Shibahara H \& Morimoto Y 2017 Quantitative and qualitative changes of mitochondria in human preimplantation embryos.
Journal of Assisted Reproduction and Genetics 34 573-580. (https://doi. org/10.1007/s10815-017-0886-6)

Hendriks WK, Colleoni S, Galli C, Paris DBBP, Colenbrander B \& Stout TAE 2019 Mitochondrial DNA replication is initiated at blastocyst formation in equine embryos. Reproduction, Fertility, and Development 31 570-578. (https://doi.org/10.1071/RD17387)

Hooijmans CR, Rovers MM, De Vries RB, Leenaars M, Ritskes-Hoitinga M \& Langendam MW 2014 SYRCLE's risk of bias tool for animal studies. BMC Medical Research Methodology 14 43. (https://doi.org/10.1186/14712288-14-43)

Hoseini FS, Salsabili N, Akbari-Asbagh F, Aflatoonian R \& AghaeeBakhtiari SH 2016 Comparison of gene expression profiles in human germinal vesicle before and after cytoplasmic transfer from mature oocytes in Iranian infertile couples. Journal of Family and Reproductive Health $1071-79$.

Hua S, Zhang Y, Li XC, Ma LB, Cao JW, Dai JP \& Li R 2007 Effects of granulosa cell mitochondria transfer on the early development of bovine embryos in vitro. Cloning and Stem Cells 9 237-246. (https://doi. org/10.1089/clo.2006.0020)

Hua S, Lu C, Song Y, Li R, Liu X, Quan F, Wang Y, Liu J, Su F \& Zhang Y 2012 High levels of mitochondrial heteroplasmy modify the development of ovine-bovine interspecies nuclear transferred embryos. Reproduction, Fertility, and Development 24 501-509. (https://doi.org/10.1071/ RD11091)

Huang CC, Cheng TC, Chang HH, Chang CC, Chen Cl, Liu J \& Lee MS 1999 Birth after the injection of sperm and the cytoplasm of tripronucleate zygotes into metaphase II oocytes in patients with repeated implantation failure after assisted fertilization procedures. Fertility and Sterility $\mathbf{7 2}$ 702-706. (https://doi.org/10.1016/s0015-0282(99)00309-x)

Huang R, Fang C, Jia L, Cao G, Zhang Z \& Liang X 2018 Mitochondrial transfer from autologous bone marrow mesenchymal stem cells improves oocyte quality. Fertility and Sterility 110 (Supplement) E190. (https://doi. org/10.1016/j.fertnstert.2018.07.556)

Igarashi H, Takahashi T, Takahashi E, Tezuka N, Nakahara K, Takahashi K \& Kurachi H 2005 Aged mouse oocytes fail to readjust intracellular adenosine triphosphates at fertilization. Biology of Reproduction 72 1256-1261. (https://doi.org/10.1095/biolreprod.104.034926)

Igarashi H, Takahashi T \& Nagase S 2015 Oocyte aging underlies female reproductive aging: biological mechanisms and therapeutic strategies. Reproductive Medicine and Biology 14 159-169. (https://doi. org/10.1007/s12522-015-0209-5)

Igarashi H, Takahashi T, Abe H, Nakano H, Nakajima O \& Nagase S 2016 Poor embryo development in post-ovulatory in vivo-aged mouse oocytes is associated with mitochondrial dysfunction, but mitochondrial transfer from somatic cells is not sufficient for rejuvenation. Human Reproduction 31 2331-2338. (https://doi.org/10.1093/humrep/dew203)

Keefe DL, Niven-Fairchild T, Powell S \& Buradagunta S 1995 Mitochondrial deoxyribonucleic acid deletions in oocytes and reproductive aging in women. Fertility and Sterility 64 577-583. (https://doi.org/10.1016/ S0015-0282(16)57796-6)

Klimczak AM, Pacheco LE, Lewis KE, Massahi N, Richards JP, Kearns WG, Saad AF \& Crochet JR 2018 Embryonal mitochondrial DNA: relationship to embryo quality and transfer outcomes. Journal of Assisted Reproduction and Genetics 35 871-877. (https://doi.org/10.1007/s10815-018-1147-z)

Knox RV 2014 Impact of swine reproductive technologies on pig and global food production. Advances in Experimental Medicine and Biology 752 131-160. (https://doi.org/10.1007/978-1-4614-8887-3_7)

Kong LH, Liu Z, Li H, Zhu L \& Xing FQ 2003 Pregnancy in a 46-year-old woman after autologous granular cell mitochondria transfer. Di Yi Jun Yi Da Xue Xue Bao 23 743, 747.

Kristensen SG, Pors SE \& Andersen CY 2017 Improving oocyte quality by transfer of autologous mitochondria from fully grown oocytes. Human Reproduction 32 725-732. (https://doi.org/10.1093/humrep/dex043)

Labarta E, De Los Santos MJ, Escribá MJ, Pellicer A \& Herraiz S 2019a Mitochondria as a tool for oocyte rejuvenation. Fertility and Sterility $\mathbf{1 1 1}$ 219-226. (https://doi.org/10.1016/j.fertnstert.2018.10.036)

Labarta E, De Los Santos MJ, Herraiz S, Escriba MJ, Marzal A, Buigues A \& Pellicer A 2019b Autologous mitochondrial transfer as a complementary technique to intracytoplasmic sperm injection to improve embryo quality in patients undergoing in vitro fertilization-a randomized pilot study. Fertility and Sterility 111 86-96. (https://doi.org/10.1016/j. fertnstert.2018.09.023) 
Lanzendorf SE, Mayer JF, Toner J, Oehninger S, Saffan DS \& Muasher S 1999 Pregnancy following transfer of ooplasm from cryopreservedthawed donor oocytes into recipient oocytes. Fertility and Sterility $\mathbf{7 1}$ 575-577. (https://doi.org/10.1016/s0015-0282(98)00504-4)

Lee WJ, Lee JH, Jeon RH, Jang SJ, Lee SC, Park JS, Lee SL, King WA \& Rho GJ 2017 Supplement of autologous ooplasm into porcine somatic cell nuclear transfer embryos does not alter embryo development. Reproduction in Domestic Animals 52 437-445. (https://doi.org/10.1111/ rda.12929)

Lei L \& Spradling AC 2013 Female mice lack adult germ-line stem cells but sustain oogenesis using stable primordial follicles. PNAS $\mathbf{1 1 0}$ 8585-8590. (https://doi.org/10.1073/pnas.1306189110)

Li R, Wen B, Zhao H, Ouyang N, Ou S, Wang W, Han J \& Yang D 2017 Embryo development after mitochondrial supplementation from induced pluripotent stem cells. Journal of Assisted Reproduction and Genetics 34 1027-1033. (https://doi.org/10.1007/s10815-017-0948-9)

Liberati A, Altman DG, Tetzlaff J, Mulrow C, Gøtzsche PC, loannidis JP, Clarke M, Devereaux PJ, Kleijnen J \& Moher D 2009 The PRISMA statement for reporting systematic reviews and meta-analyses of studies that evaluate health care interventions: explanation and elaboration. PLoS Medicine 6 e1000100. (https://doi.org/10.1371/journal.pmed.1000100)

Liu Y, Wu C, Lyu Q, Yang D, Albertini DF, Keefe DL \& Liu L 2007 Germline stem cells and neo-oogenesis in the adult human ovary. Developmental Biology 306 112-120. (https://doi.org/10.1016/j.ydbio.2007.03.006)

Liu Y, Han M, Li X, Wang H, Ma M, Zhang S, Guo Y, Wang S, Wang Y, Duan N et al. 2017 Age-related changes in the mitochondria of human mural granulosa cells. Human Reproduction 32 2465-2473. (https://doi. org/10.1093/humrep/dex309)

May-Panloup P, Chretien MF, Jacques C, Vasseur C, Malthiery Y \& Reynier P 2005 Low oocyte mitochondrial DNA content in ovarian insufficiency. Human Reproduction 20 593-597. (https://doi.org/10.1093/humrep/ deh667)

May-Panloup P, Boucret L, Chao De La Barca JM, Desquiret-Dumas V, Ferre-L'hotellier V, Moriniere C, Descamps P, Procaccio V \& Reynier $\mathbf{P}$ 2016 Ovarian ageing: the role of mitochondria in oocytes and follicles. Human Reproduction Update 22 725-743. (https://doi.org/10.1093/ humupd/dmw028)

Mishra P \& Chan DC 2014 Mitochondrial dynamics and inheritance during cell division, development and disease. Nature Reviews: Molecular Cell Biology 15 634-646. (https://doi.org/10.1038/nrm3877)

Mobarak H, Heidarpour M, Tsai PJ, Rezabakhsh A, Rahbarghazi R, Nouri M \& Mahdipour M 2019 Autologous mitochondrial microinjection; a strategy to improve the oocyte quality and subsequent reproductive outcome during aging. Cell and Bioscience 9 95. (https:// doi.org/10.1186/s13578-019-0360-5)

Motta PM, Nottola SA, Makabe S \& Heyn R 2000 Mitochondrial morphology in human fetal and adult female germ cells. Human Reproduction 15 (Supplement 2) 129-147. (https://doi.org/10.1093/ humrep/15.suppl_2.129)

Murakoshi Y, Sueoka K, Takahashi K, Sato S, Sakurai T, Tajima H \& Yoshimura Y 2013 Embryo developmental capability and pregnancy outcome are related to the mitochondrial DNA copy number and ooplasmic volume. Journal of Assisted Reproduction and Genetics 30 1367-1375. (https://doi.org/10.1007/s10815-013-0062-6)

Nagai S, Kasai T, Hirata S, Hoshi K, Yanagimachi R \& Huang T 2004 Cytoplasmic transfer in the mouse in conjunction with intracytoplasmic sperm injection. Reproductive Biomedicine Online 8 75-80. (https://doi. org/10.1016/s1472-6483(10)60500-7)

Oktay K, Baltaci V, Sonmezer M, Turan V, Unsal E, Baltaci A, Aktuna S \& Moy F 2015 Oogonial precursor cell-derived autologous mitochondria injection to improve outcomes in women with multiple IVF failures due to low oocyte quality: a clinical translation. Reproductive Sciences 22 1612-1617. (https://doi.org/10.1177/1933719115612137)

Petr J, Rozinek J, Fulka J, Jr \& Jilek F 1994 Influence of cytoplasmic microinjection on meiotic competence in growing pig oocytes. Reproduction, Nutrition, Development 34 81-87. (https://doi. org/10.1051/rnd:19940109)

Qi L, Chen X, Wang J, Lv B, Zhang J, Ni B \& Xue Z 2019 Mitochondria: the panacea to improve oocyte quality? Annals of Translational Medicine $\mathbf{7}$ 789. (https://doi.org/10.21037/atm.2019.12.02)

Qiao J, Wang ZB, Feng HL, Miao YL, Wang Q, Yu Y, Wei YC, Yan J, Wang WH, Shen $\mathbf{W}$ et al. 2014 The root of reduced fertility in aged women and possible therapentic options: current status and future perspects. Molecular Aspects of Medicine 38 54-85. (https://doi. org/10.1016/j.mam.2013.06.001)

Rastogi A, Joshi P, Contreras E \& Gama V 2019 Remodeling of mitochondrial morphology and function: an emerging hallmark of cellular reprogramming. Cell Stress 3 181-194. (https://doi.org/10.15698/ cst2019.06.189)

Reynier P, May-Panloup P, Chretien MF, Morgan CJ, Jean M, Savagner F, Barriere P \& Malthiery Y 2001 Mitochondrial DNA content affects the fertilizability of human oocytes. Molecular Human Reproduction 7 425-429. (https://doi.org/10.1093/molehr/7.5.425)

Reznichenko AS, Huyser C \& Pepper MS 2016 Mitochondrial transfer: implications for assisted reproductive technologies. Applied and Translational Genomics $11 \quad 40-47 . \quad$ (https://doi.org/10.1016/j. atg.2016.10.001)

Sansinena MJ, Lynn J, Bondioli KR, Denniston RS \& Godke RA 2011 Ooplasm transfer and interspecies somatic cell nuclear transfer: heteroplasmy, pattern of mitochondrial migration and effect on embryo development. Zygote 19 147-156. (https://doi.org/10.1017/S0967199410000419)

Santos TA, El Shourbagy S \& St John JC 2006 Mitochondrial content reflects oocyte variability and fertilization outcome. Fertility and Sterility 85 584-591. (https://doi.org/10.1016/j.fertnstert.2005.09.017)

Schatten H, Sun QY \& Prather R 2014 The impact of mitochondrial function/dysfunction on IVF and new treatment possibilities for infertility. Reproductive Biology and Endocrinology 12 111. (https://doi. org/10.1186/1477-7827-12-111)

Schon EA, Kim SH, Ferreira JC, Magalhaes P, Grace M, Warburton D \& Gross SJ 2000 Chromosomal non-disjunction in human oocytes: is there a mitochondrial connection? Human Reproduction 15 (Supplement 2) 160-172. (https://doi.org/10.1093/humrep/15.suppl_2.160)

Schultz RM \& Williams CJ 2002 The science of ART. Science 296 2188-2190. (https://doi.org/10.1126/science.1071741)

Seifer DB, Dejesus V \& Hubbard K 2002 Mitochondrial deletions in luteinized granulosa cells as a function of age in women undergoing in vitro fertilization. Fertility and Sterility 78 1046-1048. (https://doi. org/10.1016/s0015-0282(02)04214-0)

Sheng X, Yang Y, Zhou J, Yan G, Liu M, Xu L, Li Z, Jiang R, Diao Z, Zhen X et al. 2019 Mitochondrial transfer from aged adipose-derived stem cells does not improve the quality of aged oocytes in C57BL/6 mice. Molecular Reproduction and Development 86 516-529. (https://doi. org/10.1002/mrd.23129)

Shoubridge EA \& Wai T 2007 Mitochondrial DNA and the mammalian oocyte. Current Topics in Developmental Biology 77 87-111. (https:// doi.org/10.1016/S0070-2153(06)77004-1)

Srirattana K \& St John JC 2018 Additional mitochondrial DNA influences the interactions between the nuclear and mitochondrial genomes in a bovine embryo model of nuclear transfer. Scientific Reports 87246. (https://doi.org/10.1038/s41598-018-25516-3)

St John JC, Makanji Y, Johnson JL, Tsai TS, Lagondar S, Rodda F, Sun X, Pangestu M, Chen P \& Temple-Smith P 2019 The transgenerational effects of oocyte mitochondrial supplementation. Scientific Reports $\mathbf{9}$ 6694. (https://doi.org/10.1038/s41598-019-43135-4)

Steuerwald NM, Bermudez MG, Wells D, Munne S \& Cohen J 2007 Maternal age-related differential global expression profiles observed in human oocytes. Reproductive Biomedicine Online 14 700-708. (https:// doi.org/10.1016/s1472-6483(10)60671-2)

Takeda K, Tasai M, Iwamoto M, Onishi A, Tagami T, Nirasawa K, Hanada H \& Pinkert CA 2005 Microinjection of cytoplasm or mitochondria derived from somatic cells affects parthenogenetic development of murine oocytes. Biology of Reproduction 72 1397-1404. (https://doi. org/10.1095/biolreprod.104.036129)

Takeda K, Srirattana K, Matsukawa K, Akagi S, Kaneda M, Tasai M, Nirasawa K, Pinkert CA, Parnpai R \& Nagai T 2012 Influence of intergeneric/interspecies mitochondrial injection; parthenogenetic development of bovine oocytes after injection of mitochondria derived from somatic cells. Journal of Reproduction and Development $\mathbf{5 8}$ 323-329. (https://doi.org/10.1262/jrd.2011-013)

Tatone C \& Amicarelli F 2013 The aging ovary - the poor granulosa cells. Fertility and Sterility 99 12-17. (https://doi.org/10.1016/j. fertnstert.2012.11.029)

Tsai TS \& St John JC 2018 The effects of mitochondrial DNA supplementation at the time of fertilization on the gene expression profiles of porcine 
preimplantation embryos. Molecular Reproduction and Development 85 490-504. (https://doi.org/10.1002/mrd.22985)

Tsai HD, Hsieh YY, Hsieh JN, Chang CC, Yang CY, Yang JG, Cheng WL, Tsai FJ \& Liu CS 2010 Mitochondria DNA deletion and copy numbers of cumulus cells associated with in vitro fertilization outcomes. Journal of Reproductive Medicine 55 491-497.

Tsai TS, Tyagi S \& St John JC 2018 The molecular characterisation of mitochondrial DNA deficient oocytes using a pig model. Human Reproduction 33 942-953. (https://doi.org/10.1093/humrep/dey052)

Van Blerkom J, Davis PW \& Lee J 1995 ATP content of human oocytes and developmental potential and outcome after in-vitro fertilization and embryo transfer. Human Reproduction 10 415-424. (https://doi. org/10.1093/oxfordjournals.humrep.a135954)

Van Blerkom J, Sinclair J \& Davis P 1998 Mitochondrial transfer between oocytes: potential applications of mitochondrial donation and the issue of heteroplasmy. Human Reproduction 13 2857-2868. (https://doi. org/10.1093/humrep/13.10.2857)

Van Thuan N, Wakayama S, Kishigami S, Ohta H, Hikichi T, Mizutani E, Bui HT \&Wakayama T 2006 Injection of somatic cell cytoplasm into oocytes before intracytoplasmic sperm injection impairs full-term development and increases placental weight in mice. Biology of Reproduction 74 865873. (https://doi.org/10.1095/biolreprod.105.047803)

Wai T, Ao A, Zhang X, Cyr D, Dufort D \& Shoubridge EA 2010 The role of mitochondrial DNA copy number in mammalian fertility. Biology of Reproduction 83 52-62. (https://doi.org/10.1095/biolreprod.109.080887)

Wang N, Satirapod C, Ohguchi Y, Park ES, Woods DC \& Tilly JL 2017 a Genetic studies in mice directly link oocytes produced during adulthood to ovarian function and natural fertility. Scientific Reports 710011. (https://doi.org/10.1038/s41598-017-10033-6)

Wang ZB, Hao JX, Meng TG, Guo L, Dong MZ, Fan LH, Ouyang YC, Wang G, Sun QY, Ou XH et al. 2017b Transfer of autologous mitochondria from adipose tissue-derived stem cells rescues oocyte quality and infertility in aged mice. Aging 9 2480-2488. (https://doi. org/10.18632/aging.101332)

White YA, Woods DC, Takai Y, Ishihara O, Seki H \& Tilly JL 2012 Oocyte formation by mitotically active germ cells purified from ovaries of reproductive-age women. Nature Medicine 18 413-421. (https://doi. org/10.1038/nm.2669)

Xu L, Mesalam A, Lee KL, Song SH, Khan I, Chowdhury MMR, Lv W \& Kong IK 2019 Improves the in vitro developmental competence and reprogramming efficiency of cloned bovine embryos by additional complimentary cytoplasm. Cell Reprogram 21 51-60. (https://doi. org/10.1089/cell.2018.0050)

Yi YC, Chen MJ, Ho JY, Guu HF \& Ho ES 2007 Mitochondria transfer can enhance the murine embryo development. Journal of Assisted Reproduction and Genetics 24 445-449. (https://doi.org/10.1007/ s10815-007-9161-6)

Yuan J, Zhang D, Wang L, Liu M, Mao J, Yin Y, Ye X, Liu N, Han J, Gao Y et al. 2013 No evidence for neo-oogenesis may link to ovarian senescence in adult monkey. Stem Cells 31 2538-2550. (https://doi. org/10.1002/stem.1480)

Zhang H, Zheng W, Shen Y, Adhikari D, Ueno H \& Liu K 2012 Experimental evidence showing that no mitotically active female germline progenitors exist in postnatal mouse ovaries. PNAS 109 12580-12585. (https://doi. org/10.1073/pnas.1206600109)

Zhang H, Liu L, Li X, Busayavalasa K, Shen Y, Hovatta O, Gustafsson JÅ \& Liu K 2014 Life-long in vivo cell-lineage tracing shows that no oogenesis originates from putative germline stem cells in adult mice. PNAS $\mathbf{1 1 1}$ 17983-17988. (https://doi.org/10.1073/pnas.1421047111)

Zhang H, Menzies KJ \& Auwerx J 2018 The role of mitochondria in stem cell fate and aging. Development 145 dev143420. (https://doi. org/10.1242/dev.143420)

Received 19 June 2020

First decision 30 July 2020

Revised manuscript received 21 November 2020

Accepted 1 December 2020 